NBER WORKING PAPER SERIES

THE MANDARIN MODEL OF GROWTH

Wei Xiong

Working Paper 25296

http://www.nber.org/papers/w25296

\author{
NATIONAL BUREAU OF ECONOMIC RESEARCH \\ 1050 Massachusetts Avenue \\ Cambridge, MA 02138 \\ November 2018
}

I am grateful to Jianjun Miao, Yingyi Qian, and seminar participants at the 2018 Hong KongShenzhen Summer Finance Conference, the 2018 NBER Chinese Economy Meeting, Princeton, SWUFE and UIBE for helpful discussions and comments, to Lunyang Huang and Chang Liu for able research assistance, and in particular to Zheng Song for highly constructive suggestions. The views expressed herein are those of the author and do not necessarily reflect the views of the National Bureau of Economic Research.

NBER working papers are circulated for discussion and comment purposes. They have not been peer-reviewed or been subject to the review by the NBER Board of Directors that accompanies official NBER publications.

(C) 2018 by Wei Xiong. All rights reserved. Short sections of text, not to exceed two paragraphs, may be quoted without explicit permission provided that full credit, including $\odot$ notice, is given to the source. 
The Mandarin Model of Growth

Wei Xiong

NBER Working Paper No. 25296

November 2018

JEL No. E02,G18

\begin{abstract}
$\underline{\text { ABSTRACT }}$
China's economic reforms over the past 40 years have led to a mixed economic structure with the government playing a key role in an increasingly market-driven economy. This paper expands a standard growth model of Barro (1990) to incorporate this structure, with a particular focus on including the agency problem between the central and local governments. To incentivize local governors, the central government has established an economic tournament, which generates not only intended incentives to develop local economies, à la Holmstrolm (1982), but also shorttermist behaviors, à la Stein (1989). The latter channel helps to explain a series of challenges that confront the Chinese economy, such as overleverage through shadow banking and unreliable economic statistics.
\end{abstract}

\author{
Wei Xiong \\ Princeton University \\ Department of Economics \\ Bendheim Center for Finance \\ Princeton, NJ 08450 \\ and NBER \\ wxiong@princeton.edu
}


With the emergence of China as the second-largest economy in the world, there are growing demands for economists and policy makers to evaluate economic and financial risks in the Chinese economy and their potential impacts on the rest of the world. However, the economic profession is yet to develop a systematic framework that accounts for China's unique economic structure - a mixed economy with the government playing a key role in an increasingly market-driven economy. As argued by a recent review in Song and Xiong (2018), the risks and distortions originating from China's government system are particularly important for understanding a wide range of ongoing concerns about China's financial stability. The most serious concern is related to China's leverage, measured by the ratio of its outstanding debt (excluding the central government debt) relative to GDP. It quickly rose above an alarming level of 2.1 in 2015, with a substantial part of the rising leverage originating from a booming shadow banking sector. As recognized by Bai, Hsieh and Song (2016) and Chen, He and Liu (2017), this leverage boom was primarily driven by China's local governments, which only started to use debt financing from banks in 2008-2010 to implement China's massive post-crisis stimulus program. Even though the central government discouraged local governments from any further use of debt after the stimulus program ended in 2010, local governments managed to use even more debt, albeit from the less transparent shadow banking sector, to finance their investment booms.

In this paper, I expand a standard macroeconomic model to incorporate the important roles played by China's government system. China has a complex government system with the central government working along with regional governments at several levels: province, city, county, and township. As emphasized by Xu (2011) and Qian (2017), regional governments are major players in China's economic development. First, regional governments carry out over $70 \%$ of fiscal spending in China, and they are responsible for developing economic institutions and infrastructure at the regional levels, such as opening up new markets and constructing roads, highways, and airports. Second, despite their autonomy in economic and fiscal issues, regional government leaders are appointed by the central government, rather than being elected by the local electorate. As a key mechanism to incentivize regional leaders, the central government has established a tournament among officials across regions at the same level, promoting those achieving fast economic growth and penalizing those with poor performance. This system of fiscal federalism greatly stimulated China's economic growth 
by giving local officials both fiscal budgets and career incentives to develop local economies.

Specifically, I expand the growth model of Barro (1990) to incorporate this institutional structure of China's government system. I describe the basic model setting in Section 1 . The model considers an open economy with a number of regions. In each region, the representative firm has a Cobb-Douglas production function with three factors: labor, capital, and local infrastructure. The firm hires labor from local households at a competitive wage and rents capital at a given interest rate from an open capital market. By creating more infrastructure in the region, the local government can boost the productivity of the local firm. Thus, the local government faces a tradeoff in allocating its fiscal budget, which is a fixed share of local output, into investment on local infrastructure and consumption by government employees. As the local government does not internalize household consumption, it has a tendency to underinvest in infrastructure relative to the first-best benchmark, in which a social planner makes the infrastructure investment decision to maximize the social welfare of not only government employees but also the households. This underinvestment problem reflects a key agency problem between the central and local governments, which motivated the central government to establish the economic tournament among regional governors.

I introduce the economic tournament in Section 2, which indeed helps to mitigate underinvestment in infrastructure. As the output from each region reflects the ability of its governor and the aggregate economic shock to the country, the central government uses the output from all regions at the end of each period to jointly assess the ability and determine career advancement of all regional governors. As more investment on infrastructure improves regional output, the tournament generates an implicit incentive for each governor to invest in infrastructure through the "signal-jamming mechanism" coined by Holmstrolm (1982), due to the inability of the central government to fully separate the contribution of a governor's ability and infrastructure investment to the regional output. This incentive serves as a powerful mechanism to drive China's economic growth, as highlighted by the literature on the Chinese economy, e.g., Li and Zhou (2005).

More interestingly, the powerful incentives induced by the tournament may also lead local governments to engage in short-termist behaviors, which help to explain various challenges that currently confront the Chinese economy. First, despite its advanced information technology, China still lacks reliable statistics about its economy. As discussed by Hor- 
tacsu, Liang and Zhou (2017) and Bai et al. (2018), the sum of China's provincial GDP has been routinely higher than the national GDP by a substantial amount - around 5 percentsince 2004. This enormous discrepancy cannot simply be attributed to measurement errors. Instead, it is deeply rooted in the government bureaucracy, as regional governments can influence local statistics bureaus, which report local economic statistics. In Section 3, I extend the model to capture this phenomenon by making the central government reliant on regional governors to report regional output, which is, in turn, used to evaluate their performance and to determine the region's tax transfer to the central government. Consequently, career concerns motivate each regional governor to overreport regional output, at the expense of a higher tax transfer to the central government. This mechanism is similar in spirit to overreporting of earnings by executives of publicly listed firms, e.g., Stein (1989).

The tournament among regional governors also helps to explain the aforementioned rising leverage across China. To address this issue, I further expand the model in Section 4 to allow each regional government to use debt financing to expand its fiscal budget. The regional governor faces an intertemporal tradeoff in using more debt to finance more infrastructure investment. On one hand, by taking advantage of a high growth rate of regional productivity, it benefits the households (a social motive) and boosts his personal career (a private motive). On the other hand, it requires a higher debt payment in the next period. While a certain level of debt is socially beneficial when the local productivity growth rate is sufficiently high, my model also shows that a governor's career concerns can lead to overinvestment by using excessive leverage.

My model also offers an intricate mechanism of spillover of excessive leverage from one region to other regions. Under the assumption of rational expectations, the central government is able to fully anticipate short-termist behaviors of each regional government, such as output overreporting and excessive use of leverage, and thus insulate the relative performance evaluations of other governors from such behaviors. This assumption is unrealistic under China's institutional environment, in which frequent policy innovations and financial innovations give local governments ample flexibility out of sight of the central government. A more realistic assumption is that the central government can only realize local governments' short-termist behaviors with a delay, as consistent with China's gradualistic approach to economic reform. I incorporate this more realistic feature in Section 5 . As a result, the 
short-termist behavior of one governor adversely affects the relative performance evaluation of other governors, which, in turn, leads to a rat race between the governors in pursuing even higher levels of leverage in their regions.

Overall, this "Mandarin" model is defined by two key features of the Chinese economy. First, the government takes a central role in driving the economy through its active investment in infrastructure, which can be interpreted more broadly as measures and policies by the government to support and stimulate economic development. Second, agency problems in the government system can lead to a rich set of phenomena in the Chinese economy - not only rapid economic growth propelled by the tournament among local governors, but also short-termist behaviors of local governors that directly affect China's economic and financial stability.

In Section 6, I also provide two stylized facts that support the key notions of the Mandarin model. First, based on data reported by the national audit of local government leverage by the Ministry of Finance, I find that across different provinces, there is a negative relationship between local government leverage and return to capital. This negative relationship supports the basic notion of our model that career concerns lead local governors to overinvest by using excessive leverage. Second, by using the estimates of provincial GDP overreporting provided by Bai et al. (2018), I show that across provinces, there is a positive relationship between GDP overreporting and local government leverage, which supports another key notion of my model that career concerns lead local governors to pursue both GDP overreporting and excessive leverage.

My work builds on the literature that studies China's institutional reform. Lau, Qian and Roland (2000) analyze the optimality of the dual-track reform approach adopted by China in allowing private firms to coexist and compete with state firms. The work of Maskin, Qian and $\mathrm{Xu}(2000)$ is particularly close to mine as it justifies the effectiveness of the tournament competition in motivating local officials. There is also substantial empirical evidence showing that local economic performance, such as GDP growth, is significantly correlated with the career incentives of local officials, e.g., Li and Zhou (2005) and Yu, Zhou and Zhu (2016). Building on these theoretical and empirical results, my model embeds China's institutional system into a macroeconomic framework and further highlights various short-termist behaviors induced by local officials' career concerns and tournament competition. 
This unique focus also differentiates my model from other work analyzing China's macroeconomy. Brandt and Zhu (2000) highlight the government's commitment to support employment in inefficient state firms through money creation as a key driver of inflationary pressure in China. Song, Storesletten and Zilibotti (2011) develop a macroeconomic model for how financial frictions cause banks to favor state firms and discriminate against more efficient private firms, leading to a puzzling observation of a fast-growing country exporting capital to other countries. Li, Liu and Wang (2015) develop a general equilibrium model to show how state firms, despite being less efficient, managed to earn more profits than private firms by monopolizing upstream industries and extracting rent from more liberalized downstream industries. Hsieh and Klenow (2010) measure misallocation of capital and labor in China. Young (2003) and Zhu (2012) provide growth accounting of China. Hsieh and Song (2015) analyze the transformation of state firms during China's economic reform. Cheremukhin et al. (2017) use a neoclassical two-sector growth model with wedges to analyze growth in China's pre-reform years in 1953-1978.

My paper also adds to the literature on the effects of government spending on economic growth, e.g., Barro (1990), Easterly and Rebelo (1993), and Glomm and Ravikumar (1994). This literature is mostly agnostic about the institutional structure of the government system that supports government spending and infrastructure development. In contrast, my model highlights the tournament competition among regional governments in driving infrastructure investment, as well as short-termist behaviors, which may eventually aggregate to substantial macro effects at the national level.

\section{The Basic Setting}

I consider an economy with $M$ regions and infinitely many periods $t=0,1,2 \ldots$ I employ a standard setting of Barro (1990) with infrastructure as public goods provided by the local government in each region. In region $i(i=1, \ldots, M)$, the local output is determined by the production of a representative firm:

$$
Y_{i t}=A_{i t} K_{i t}^{\alpha_{i}} L_{i t}^{1-\alpha_{i}} G_{i t}^{1-\alpha_{i}}
$$

where $A_{i t}$ is the local productivity, $K_{i t}$ is the capital used for production, $L_{i t}$ is the local labor input. The parameters $\alpha_{i} \in(0,1)$ and $1-\alpha_{i}$ are the output shares of capital and labor, 
respectively. In this section, I simply assume that the local productivity $A_{i t}$ in one region is identically and independently distributed over time, without imposing any structure on the productivities across regions. From the next section on, I will specify a particular structure with a common productivity shock affecting the productivities of all regions.

The third factor $G_{i t}$ is infrastructure created by the local government. It serves as a public good that boosts the local productivity. One may interpret $G_{i t}$ as electricity, roads, bridges, ports, and highways. ${ }^{1}$ As I will show, the firm chooses capital and labor based on the level of local infrastructure. $G_{i t}$ thus serves as a direct channel for government investment to drive the economy. After accounting for firms' capital and labor choices, the regional economy displays a constant return with respect to $G_{i t}$, a feature that resembles the endogenous growth model of Romer (1986).

\section{$1.1 \quad$ Households and Firms}

In any given region $i$, there are overlapping generations of households, as in Diamond (1965). Each generation of households lives for two periods, and each individual born at $t$ has identical preferences represented by

$$
\ln \left(C_{i t}^{t}\right)+\beta \ln \left(C_{i t+1}^{t}\right),
$$

where $C_{i t}^{t}$ and $C_{i t+1}^{t}$ represent consumption chosen by the individual across his lifetime at $t$ and $t+1$. The parameter $\beta \in(0,1)$ is the individual's time discount rate for the next period's consumption. This OLG specification with logarithmic utility simplifies household decisions, but is inconsequential to our key insight.

Each individual supplies one unit of labor when he is young, i.e., $L_{i t}=1$, at a competitive wage and divides his wage income between consumption $C_{i t}^{t}$ and savings $S_{i t}^{t}$ :

$$
C_{i t}^{t}+S_{i t}^{t} \leq(1-\tau) \Phi_{i t} L_{i t},
$$

where $\Phi_{i t}$ is the competitive wage and $\tau$ is the tax rate on both labor and capital income. I adopt a small open economy setting for the region so that the savings are invested at the

\footnotetext{
${ }^{1}$ Bai and Qian (2010) provide a detailed account of China's development of infrastructure in three sectors: electricity, highways, and railways. Zhang and Barnett (2014) show that infrastructure investment contributed to nearly $15 \%$ of China's GDP in $2008-2012$.
} 
constant gross interest rate $R>1$ for the next period's consumption:

$$
C_{i t+1}^{t}=(1-\tau) R S_{i t}^{t}
$$

Throughout the paper, I consider the whole economy in the country as a small open economy with the interest rate $R$ being exogenously given by the global market.

The standard result for log utility implies that the individual consumes a fixed fraction of his labor income in the current period and saves the rest for the next period:

$$
\begin{aligned}
C_{i t}^{t} & =\frac{1}{1+\beta}(1-\tau) \Phi_{i t} L_{i t}, \\
S_{i t}^{t} & =\frac{\beta}{1+\beta}(1-\tau) \Phi_{i t} L_{i t} .
\end{aligned}
$$

I assume that firms in the region are homogenous. In each period, the representative firm in the region first observes the current period productivity $A_{i t}$ and then hires capital and labor to maximize its profit:

$$
\max _{\left\{K_{i t}, L_{i t}\right\}} A_{i t} K_{i t}^{\alpha_{i}} L_{i t}^{1-\alpha_{i}} G_{i t}^{1-\alpha_{i}}-\Phi_{i t} L_{i t}-R K_{i t},
$$

where $W_{i t}$ is the competitive wage and $R$ is the rental rate of capital, which is equal to the interest rate. Note that I assume that tax is levied on labor and capital incomes rather than on firms.

Given the supply of labor $L_{i t}=1$, the first-order condition implies that the competitive wage is determined by the marginal product of labor:

$$
\Phi_{i t}=\left(1-\alpha_{i}\right) A_{i t} K_{i t}^{\alpha_{i}} G_{i t}^{1-\alpha_{i}} .
$$

By equating the marginal product of capital with the rental rate of capital, I can determine the firm's optimal capital by the firm's productivity, the capital rental rate, and the local infrastructure:

$$
K_{i t}=\left(\frac{\alpha_{i} A_{i t}}{R}\right)^{1 /\left(1-\alpha_{i}\right)} G_{i t} .
$$

By substituting $L_{i t}$ and $K_{i t}$ back to the output and market wage, I have

$$
Y_{i t}=\left(\frac{\alpha_{i}}{R}\right)^{\alpha_{i} /\left(1-\alpha_{i}\right)} A_{i t}^{1 /\left(1-\alpha_{i}\right)} G_{i t} .
$$

The firm's optimal capital choice and output are both proportional to local infrastructure $G_{i t}$, which is developed by the local government. Thus, by developing local infrastructure, 
the local government can directly stimulate firms to expand their capital investment and raise the labor wage. Furthermore, the production technology of the local economy is essentially an AK technology with respect to infrastructure stock $G_{i t}$.

Note that $\Phi_{i t} L_{i t}=\left(1-\alpha_{i}\right) Y_{i t}$. Thus, for an individual born at time $t$, his current consumption and next-period consumption are both proportional to $G_{i t}$ :

$$
\begin{aligned}
C_{i t}^{t} & =\frac{1}{1+\beta}\left(1-\alpha_{i}\right)(1-\tau) Y_{i t} \\
& =\frac{1}{1+\beta}\left(1-\alpha_{i}\right)(1-\tau)\left(\frac{\alpha_{i}}{R}\right)^{\alpha_{i} /\left(1-\alpha_{i}\right)} A_{i t}^{1 /\left(1-\alpha_{i}\right)} G_{i t},
\end{aligned}
$$

and

$$
\begin{aligned}
C_{i t+1}^{t} & =\frac{\beta}{1+\beta} R\left(1-\alpha_{i}\right)(1-\tau)^{2} Y_{i t} \\
& =\frac{\beta}{1+\beta} R\left(1-\alpha_{i}\right)(1-\tau)^{2}\left(\frac{\alpha_{i}}{R}\right)^{\alpha_{i} /\left(1-\alpha_{i}\right)} A_{i t}^{1 /\left(1-\alpha_{i}\right)} G_{i t} .
\end{aligned}
$$

\subsection{Local Government}

I assume that the country adopts a system of fiscal federalism. Specifically, the local government of each region collects tax and uses the tax revenue for developing local infrastructure and funding its own consumption. For simplicity, this paper ignores the fiscal spending of the central government.

Tax is collected from labor and capital income at a rate of $\tau$. Thus, the local government's tax revenue in period $t$ is $\tau\left(\Phi_{i t} L_{i t}+R K_{i t}\right)=\tau Y_{i t}$, which contributes to its budget at the end of period $t$ :

$$
W_{i t}=\tau Y_{i t}+\left(1-\delta_{G}\right) G_{i t}
$$

with $\delta_{G} \in[0,1]$ as the depreciation rate of infrastructure and $\left(1-\delta_{G}\right) G_{i t}$ as the infrastructure stock after depreciation. As the government employs a large number of employees, a fraction of this budget has to be spent for the benefit of government employees. Thus, the local governor needs to allocate the budget between infrastructure for the following period $G_{i t+1}$ and consumption by government employees $E_{i t}^{G}>0$ in the current period:

$$
G_{i t+1}+E_{i t}^{G}=W_{i t}
$$

For simplicity, I ignore other types of government spending. Note that $E_{i t}^{G}$ benefits government employees, but does not directly serve the households. In contrast, the infrastructure 
$G_{i t+1}$ serves the welfare of both government employees and households as it increases the productivity of the local economy.

I assume that the local government aims to maximize the following Bellman equation:

$$
V\left(W_{i t}\right)=\max _{E_{i t}^{G}} E_{t}\left[\gamma \ln \left(E_{i t}^{G}\right)+\beta V\left(W_{i t+1}\right)\right],
$$

subject to the budget constraint in (4). In this specification, the government only maximizes the private benefit of government employees without caring about the welfare of the households. The government also has a log utility function for its private benefit. The parameter $\gamma>0$ is redundant in this Bellman equation for the government choice, but serves to measure the weight assigned to government employees in the first-best benchmark. The expectation operation $E_{t}[\cdot]$ represents the conditional expectation at time $t$ after the current-period productivity $A_{i t}$ and output $Y_{i t}$ are observed. The value function $V\left(W_{i t}\right)$ captures the welfare of the government employees from period $t$ onwards, with $W_{i t}$ as the state variable to capture the local government's current-period budget.

Note the following remarks on the setting: First, I allow the government to divest its infrastructure without any cost, i.e., $G_{i t}$ can be smaller than $\left(1-\delta_{G}\right) G_{i t-1}$. Second, in this section, I assume that the government cannot borrow or save and must spend its budget in each period on either infrastructure investment or government consumption. I relax this assumption in Sections 4 and 5 by allowing the government to use debt. Third, the government's investment decision at time $t$ determines the level of infrastructure at $t+1$. This feature is realistic as infrastructure usually takes time to build.

As the governor is constrained from borrowing or saving, he faces an intertemporal tradeoff in allocating his current-period budget on either infrastructure investment or government consumption. If he allocates more to infrastructure investment (i.e., a higher $G_{i t+1}$ ), the local output and tax revenue in the next period are higher, trading off less current-period government consumption. By directly solving the Bellman equation, Proposition 1 summarizes the governor's optimal investment rule.

Proposition 1 In each period, the local government allocates a fixed fraction $\beta$ of its budget to local infrastructure:

$$
G_{i t+1}=\beta\left[\tau Y_{i t}+\left(1-\delta_{G}\right) G_{i t}\right] .
$$


This simple setting captures a mixed economic structure - the local government drives the regional economy by building up local infrastructure, while local firms make capital and labor choices in response to the government's infrastructure investment. Thus, by investing more into local infrastructure, the local government can stimulate more investments from local firms. One may broadly interpret infrastructure in this model as including not only physical infrastructure, such as roads and ports, but also intangible infrastructure such as policies and systems that local governments develop to improve the local economic and business environment.

\subsection{The First-Best Benchmark}

Given the local government's self interest in spending the tax revenue, its infrastructure choice does not consider the welfare of the households and thus is not socially optimal. For comparison, I now analyze the first-best benchmark. Specifically, I consider a social planner, who aims to maximize the welfare of the households in addition to that of the government employees. In each period, I let the social planner, rather than the local government, make the infrastructure decision. Then, given the infrastructure level, the representative firm makes its capital and labor choices, as in the main setting. That is, at time $t$, the firm

chooses its capital after observing the local government's infrastructure choice $G_{i t}$ and the local productivity $A_{i t}$ as given in (2), and offers a competitive wage, as given in (1), so that $L_{i t}=1$. Consequently, the output is given by (3).

The social planner allocates the aggregate social budget in the local economy

$$
W_{i t}^{\text {planner }}=Y_{i t}+\left(1-\delta_{G}\right) G_{i t}
$$

to the young generation consumption $C_{i t}^{t}$, to the old generation consumption $C_{i t}^{t-1}$, to the government consumption $E_{i t}^{G}$, and to infrastructure $G_{i t+1}$ :

$$
W_{i t}^{\text {planner }}=C_{i t}^{t}+C_{i t}^{t-1}+E_{i t}^{G}+G_{i t+1}
$$

to maximize

$$
V\left(W_{i t}^{\text {planner }}\right)=\max _{C_{i t}^{t}, C_{i t}^{t-1}, E_{i t}^{G}, G_{i t+1}} E_{t}\left[\ln \left(C_{i t}^{t}\right)+\ln \left(C_{i t}^{t-1}\right)+\gamma \ln E_{i t}^{G}+\beta V\left(W_{i t+1}^{\text {planner }}\right)\right] .
$$

As mentioned earlier, the parameter $\gamma$ measures the weight of the government employees in the social welfare. 
The following proposition states the result from solving the planner's Bellman equation:

Proposition 2 In the first-best benchmark, the social planner allocates a fixed fraction $\beta$ of the aggregate social budget to infrastructure:

$$
G_{i t+1}=\beta\left[Y_{i t}+(1-\delta) G_{i t}\right] .
$$

A comparison of Propositions 1 and 2 shows that the local government underinvests in infrastructure relative to the first-best level. This is because the local government does not internalize the consumption of the households in its infrastructure choice. As a result, it allocates only a fixed fraction $\beta$ of its fiscal budget to infrastructure. In contrast, the social planner allocates a fraction $\beta$ of the social budget to infrastructure. This underinvestment reveals a fundamental agency problem between the central and local governments, and motivates the central government to use the economic tournament to mitigate the agency problem.

\section{Career Concerns}

Different from the typical federal government system in other countries, regional governors in China are appointed by the central government rather than elected by a local electorate. As eloquently summarized by Xu (2011) and Qian (2017), by giving local governments large fiscal independence and evaluating them based on a common set of criteria that weigh heavily on local economic performance, regional governors are greatly incentivized to become helping hands, rather than grabbing hands, in developing local economies. This economic tournament is widely recognized as a key mechanism contributing to China's rapid growth over the past 40 years.

In typical western countries, career concerns of politicians who aim to win local elections may also generate incentives to develop local economies. Such incentives vary across regions depending on the preferences and interests of local electorates. For example, voters in one region may care more about economic growth, thus leading to greater incentives for the local politicians to develop local economy, while voters in another region may care more about the environment, leading the local politicians to give lower priority to developing the economy. Having the central government as the common evaluator of all regional governors in China 
dictates that they all share the same career incentives and thus compete directly with each other.

To incorporate the tournament, I adopt the following specification of the productivity of region $i$ :

$$
A_{i t}=e^{f_{t}+a_{i t}+\varepsilon_{i t}}
$$

where $f_{t} \sim N\left(\bar{f}, \sigma_{f}^{2}\right)$ represents a countrywide common shock with Gaussian distribution of mean $\bar{f}$ and variance $\sigma_{f}^{2}, a_{i t} \sim N\left(\bar{a}_{i}, \sigma_{a}^{2}\right)$ represents the governor's ability in developing the local economy, which has Gaussian distribution of mean $\bar{a}_{i}$ and variance $\sigma_{a}^{2}$, and $\varepsilon_{i t} \sim$ $N\left(0, \sigma_{\varepsilon}^{2}\right)$ is an idiosyncratic noise component, again with Gaussian distribution of mean 0 and variance $\sigma_{\varepsilon}^{2}$. These components are independent of each other, and neither of them is publicly observable. Furthermore, their distributions are common knowledge to all agents.

I assume that a new governor, randomly drawn from the distribution $N\left(\bar{a}_{i}, \sigma_{a}^{2}\right)$, is assigned to a region in each period. The governor works in the region for only one period and is concerned about the central government's perception of his ability after observing his performance and his peers' performance. Specifically, suppose that a governor takes over region $i$ at the end of period $t$ after $Y_{i t}$ is realized, and chooses $E_{i t}^{G}$ and $G_{i t+1}$. As the governor's ability affects the local productivity at $t+1$, the local output $Y_{i t+1}$ provides useful information about his ability when his term ends at $t+1$. That is, his performance is determined by

$$
\widehat{a}_{i t+1}=E\left[a_{i t+1} \mid\left\{Y_{i t+1}\right\}_{i=1, \ldots, M}\right]
$$

By substituting in $Y_{i t+1}$ from (3), I obtain

$$
\begin{aligned}
y_{i t+1} & =\ln \left(Y_{i t+1}\right)=\ln \left[\left(\frac{\alpha_{i}}{R}\right)^{\alpha_{i} /\left(1-\alpha_{i}\right)} A_{i t+1}^{1 /\left(1-\alpha_{i}\right)} G_{i t+1}\right] \\
& =\frac{1}{1-\alpha_{i}}\left(f_{t+1}+a_{i t+1}+\varepsilon_{i t+1}\right)+\frac{\alpha_{i}}{1-\alpha_{i}} \ln \left(\frac{\alpha_{i}}{R}\right)+\ln \left(G_{i t+1}\right) .
\end{aligned}
$$

Equation (7) shows that the local output $\ln \left(Y_{i t+1}\right)$ provides a useful signal about the governor's ability $a_{i t+1}$. As the governor can boost the local output by taking on more infrastructure investment, the governor's career concerns give an incentive to invest more in infrastructure, overcoming his preference for more government consumption. The career concerns thus provide an implicit incentive to invest in local infrastructure, as in the spirit of Holmstrolm (1982) and Gibbons and Murphy (1992). 
To analyze this mechanism, I assume that the central government cannot observe the stock of local infrastructure (i.e., $\left.G_{i t+1}\right)$ and other input in local production. Instead, it observes only the output level $Y_{i t+1}$. This assumption is realistic for several reasons. First, the central government has to rely on local statistics bureaus to report local statistics. As local governments have strong influences on local statistics bureaus, they have ample flexibility to manage or even distort local statistics. Second, the National Bureau of Statistics devotes a great deal of effort to auditing and verifying regional output, as it is a key variable for many policy decisions of the central government. As a result, it is harder to distort output statistics than other factor statistics. Motivated by these observations, I assume for the rest of the paper that the central government can only use regional output to evaluate the performance of local governors. Note that I will further modify the setting to allow local governors to overreport regional output in Section 3, even though it is not manipulatable in other sections.

Following Holmstrolm (1982), I assume that the central government has rational expectations and anticipates the local governor will choose a level of infrastructure $G_{i t+1}$, which is equal to its equilibrium level $G_{i t+1}^{*}$. As a result, in interpreting the observed output, the central government would simply deduct $\ln \left(G_{i t+1}^{*}\right)$ from the observed log output $y_{i t+1}$, even though it does not directly observe the governor's actual choice $G_{i t+1}$, by constructing the following sufficient statistic:

$$
\begin{aligned}
z_{i t+1} & \equiv\left(1-\alpha_{i}\right)\left\{y_{i t+1}-\left[\frac{\alpha_{i}}{1-\alpha_{i}} \ln \left(\frac{\alpha_{i}}{R}\right)+\ln \left(G_{i t+1}^{*}\right)\right]\right\} \\
& =f_{t+1}+a_{i t+1}+\varepsilon_{i t+1}+\left(1-\alpha_{i}\right)\left[\ln \left(G_{i t+1}\right)-\ln \left(G_{i t+1}^{*}\right)\right] .
\end{aligned}
$$

From the central government's perspective, the governor would choose $G_{i t+1}=G_{i t+1}^{*}$, and consequently

$$
z_{i t+1}=f_{t+1}+a_{i t+1}+\varepsilon_{i t+1}
$$

In Section 5, I will relax the rational expectations assumption to consider a more realistic setting in which the central government can only realize the infrastructure and debt choices of local governments with a delay.

Due to the common shock in each region's productivity, the central government will use the outputs from all regions to jointly infer each governor's ability. This joint evaluation leads to a tournament in which each governor's performance is compared with that of other 
governors. By directly applying the Bayes Theorem based on the composition of $z_{i t+1}$ given in (9), I obtain the following learning rule for the central government:

$$
\begin{aligned}
& \hat{a}_{i t+1} \\
= & E\left[a_{i t+1} \mid\left\{z_{i t+1}\right\}_{i=1, \ldots, M}\right] \\
= & \bar{a}_{i}+\frac{\sigma_{a}^{2}\left(\sigma_{a}^{2}+\sigma_{\varepsilon}^{2}+(M-1) \sigma_{f}^{2}\right)}{\left(\sigma_{a}^{2}+\sigma_{\varepsilon}^{2}\right)\left(\sigma_{a}^{2}+\sigma_{\varepsilon}^{2}+M \sigma_{f}^{2}\right)}\left(z_{i t+1}-\bar{z}_{i t+1}\right)-\frac{\sigma_{a}^{2} \sigma_{f}^{2}}{\left(\sigma_{a}^{2}+\sigma_{\varepsilon}^{2}\right)\left(\sigma_{a}^{2}+\sigma_{\varepsilon}^{2}+M \sigma_{f}^{2}\right)} \sum_{j \neq i}\left(z_{j t+1}-\bar{z}_{j t+1}\right) .
\end{aligned}
$$

From the governor's perspective, $z_{i t+1}$ depends on his own choice $G_{i t+1}$ in (8). As a result, the governor can influence the central government's perception $\hat{a}_{i t+1}$ by choosing a higher level of $G_{i t+1}$ at time $t$. By substituting in $z_{i t+1}$ from (8), I have

$$
\begin{aligned}
& \hat{a}_{i t+1}-\bar{a}_{i} \\
= & \frac{\sigma_{a}^{2}\left(\sigma_{a}^{2}+\sigma_{\varepsilon}^{2}+(M-1) \sigma_{f}^{2}\right)}{\left(\sigma_{a}^{2}+\sigma_{\varepsilon}^{2}\right)\left(\sigma_{a}^{2}+\sigma_{\varepsilon}^{2}+M \sigma_{f}^{2}\right)}\left[\left(f_{t+1}-\bar{f}\right)+\left(a_{i t+1}-\bar{a}_{i}\right)+\varepsilon_{i t+1}+\left(1-\alpha_{i}\right)\left(\ln G_{i t+1}-\ln G_{i t+1}^{*}\right)\right] \\
& -\frac{\sigma_{a}^{2} \sigma_{f}^{2}}{\left(\sigma_{a}^{2}+\sigma_{\varepsilon}^{2}\right)\left(\sigma_{a}^{2}+\sigma_{\varepsilon}^{2}+M \sigma_{f}^{2}\right)} \\
& \cdot \sum_{j \neq i}\left[\left(f_{t+1}-\bar{f}\right)+\left(a_{j t+1}-\bar{a}_{j}\right)+\varepsilon_{j t+1}+\left(1-\alpha_{j}\right)\left(\ln G_{j t+1}-\ln G_{j t+1}^{*}\right)\right] .
\end{aligned}
$$

This expression shows that choosing a higher $G_{i t+1}$ affects the central government's perception, even though the central government rationally anticipates such behavior in equilibrium, as reflected by its anticipation of $G_{i t+1}=G_{i t+1}^{*}$. This is the basic insight of the signal-jamming mechanism highlighted by Holmstrolm (1982).

To capture the governor's career concern induced by the tournament, I introduce an additional term into the local government's Bellman equation previously specified in (5):

$$
V\left(W_{i t}\right)=\max _{G_{i t+1}} E_{t}\left[\gamma \ln \left(W_{i t}-G_{i t+1}\right)+\chi_{i}\left(\hat{a}_{i t+1}-\bar{a}_{i}\right)+\beta V\left(\tau Y_{i t+1}+\left(1-\delta_{G}\right) G_{i t+1}\right)\right]
$$

where $\chi_{i}\left(\hat{a}_{i t+1}-\bar{a}_{i}\right)$ is the new term with $\chi_{i}>0$ as the weight assigned to the governor's career concerns. ${ }^{2}$ In formulating this Bellman equation, I implicitly assume that while the governor changes in each period, other employees of the local government will remain. As these government employees care about their future consumption, they will ensure that the

\footnotetext{
${ }^{2}$ One may micro-found this term by assuming that the central government randomly pairs each governor with another governor and promotes the one with better perception. Linearizing the expected promotion probability leads to the linear term specified in the objective.
} 
governor's infrastructure choice accounts for their future welfare, as reflected by the last term in the Bellman equation.

With the additional career concern term, the relevant terms in the governor's objective for choosing $G_{i t+1}$ on the right-hand side of the Bellman equation (11) are

$\max _{G_{i t+1}} E_{t}\left[\gamma \ln \left(W_{i t}-G_{i t+1}\right)+\kappa_{i} \ln G_{i t+1}+\beta V\left(\left(1-\delta_{G}\right) G_{i t+1}+\tau\left(\frac{\alpha_{i}}{R}\right)^{\alpha_{i} /\left(1-\alpha_{i}\right)} A_{i t+1}^{1 /\left(1-\alpha_{i}\right)} G_{i t+1}\right)\right]$

where

$$
\kappa_{i}=\frac{\sigma_{a}^{2}\left(\sigma_{a}^{2}+\sigma_{\varepsilon}^{2}+(M-1) \sigma_{f}^{2}\right)}{\left(\sigma_{a}^{2}+\sigma_{\varepsilon}^{2}\right)\left(\sigma_{a}^{2}+\sigma_{\varepsilon}^{2}+M \sigma_{f}^{2}\right)}\left(1-\alpha_{i}\right) \chi_{i} .
$$

These terms are almost the same as those from the Bellman equation in (5), except for the additional term $\kappa_{i} \ln G_{i t+1}$ in the first bracket, which addresses the governor's career concerns. By solving the Bellman equation, I obtain the optimal infrastructure as summarized in the next proposition:

Proposition 3 The governor's career concerns lead to greater infrastructure investment:

$$
G_{i t+1}=\left[\frac{\kappa_{i}}{\gamma+\kappa_{i}}(1-\beta)+\beta\right]\left(\tau Y_{i t}+\left(1-\delta_{G}\right) G_{i t}\right) .
$$

Proposition 3 shows that career concerns motivate the governor to choose a greater level of infrastructure investment. In particular, a governor with a higher $\chi_{i}$ coefficient invests more into infrastructure. Thus, the tournament helps to overcome the underinvestment problem to infrastructure, as derived in Proposition 1 for the case in which the local government only cares about government consumption. This simple result provides the institutional foundation for China's rapid growth, which builds on strong career incentives for local governors to develop local economies.

Career concerns not only lead to positive incentives of developing local infrastructure but also to other short-termist behaviors. In the subsequent sections, I analyze such short-termist behaviors.

\section{Output Overreporting}

China has a multi-level structure for reporting economic statistics. The National Bureau of Statistics (NBS) reports national statistics, while local statistics bureaus, which are subject to strong influence from local governments, report local statistics. Hortaçsu, Liang and 
Zhou (2017) and Bai et al. (2018) report that the sum of provincial GDP has been routinely higher than the national GDP by an amout in the order of five percent of national GDP. This substantial gap suggests that local statistics bureaus in aggregate overreport provincial GDP. Furthermore, Bai et al. (2018) provide forensic analysis of overreporting of provincial GDP and capital investment.

In this section, I analyze overreporting of regional output induced by the career concerns of local governors. To examine this issue, I modify the model setting by assuming that the central government does not directly observe the regional output in the current period. Instead, each governor reports the output of his region to the central government. This gives each governor the flexibility to inflate his performance. To discipline overreporting, the central government takes away a fraction of the reported output as tax revenue to fund central government spending. This assumption is consistent with the split tax arrangement between the central government and local governments in China. Thus, from the perspective of a regional governor, overreporting the local output comes at the cost of a larger tax transfer to the central government. ${ }^{3}$

Specifically, I assume that a governor is free to report $Y_{i t}^{\prime}$ as the output of his region, which may be different from the actual output $Y_{i t}$. Or equivalently, the governor may choose to report the log output $y_{i t}^{\prime}$, which is different from the actual log output $y_{i t}$ by an amount $\varphi_{i t}:$

$$
y_{i t}^{\prime}=y_{i t}+\varphi_{i t}
$$

With the actual output given by (7), the reported output is

$$
y_{i t}^{\prime}=\frac{1}{1-\alpha_{i}}\left(f_{t}+a_{i t}+\varepsilon_{i t}\right)+\frac{\alpha_{i}}{1-\alpha_{i}} \ln \left(\frac{\alpha_{i}}{R}\right)+\ln \left(G_{i t}\right)+\varphi_{i t} .
$$

In interpreting the reported output, the central government anticipates the governor will invest $G_{i t}^{*}$ in infrastructure and overreport by $\varphi_{i t}^{*}$ and thus constructs the following sufficient

\footnotetext{
${ }^{3}$ In 2017-2018, several provinces including Liaoning, Inner Mongolia and Tianjing publicly acknowledged their overreporting in the previous years, partly due to large shortfalls in their fiscal revenues, as GDP over-reporting further reduced the tax revenues of these provinces. This feature is also consistent with the finding of Fan, Xiong and Zhou (2016) that during the Great Famine of China in 1959-1961, overreporting of regional grain output by local governments led to greater procurement of grain to the central government and more severe famine in the region.
} 
statistic:

$$
\begin{aligned}
z_{i t}^{\prime} & \equiv\left(1-\alpha_{i}\right)\left\{y_{i t}^{\prime}-\left[\frac{\alpha_{i}}{1-\alpha_{i}} \ln \left(\frac{\alpha_{i}}{R}\right)+\ln \left(G_{i t}^{*}\right)\right]-\varphi_{i t}^{*}\right\} \\
& =f_{t}+a_{i t}+\varepsilon_{i t}+\left(1-\alpha_{i}\right)\left[\ln \left(G_{i t}\right)-\ln \left(G_{i t}^{*}\right)+\left(\varphi_{i t}-\varphi_{i t}^{*}\right)\right] .
\end{aligned}
$$

With rational expectations, the central government expects the governor's choices $G_{i t}=G_{i t}^{*}$ and $\varphi_{i t}=\varphi_{i t}^{*}$, thus it views

$$
z_{i t}^{\prime}=f_{t}+a_{i t}+\varepsilon_{i t}
$$

Consequently, I have the same learning rule for the central government as before:

$$
\begin{aligned}
& \hat{a}_{i t+1}-\bar{a}_{i} \\
= & E\left[a_{i t+1} \mid\left\{z_{i t+1}^{\prime}\right\}_{i=1, \ldots, M}\right]-\bar{a}_{i} \\
= & \frac{\sigma_{a}^{2}\left(\sigma_{a}^{2}+\sigma_{\varepsilon}^{2}+(M-1) \sigma_{f}^{2}\right)}{\left(\sigma_{a}^{2}+\sigma_{\varepsilon}^{2}\right)\left(\sigma_{a}^{2}+\sigma_{\varepsilon}^{2}+M \sigma_{f}^{2}\right)}\left(z_{i t+1}^{\prime}-\bar{z}_{i t+1}\right)-\frac{\sigma_{a}^{2} \sigma_{f}^{2}}{\left(\sigma_{a}^{2}+\sigma_{\varepsilon}^{2}\right)\left(\sigma_{a}^{2}+\sigma_{\varepsilon}^{2}+M \sigma_{f}^{2}\right)} \sum_{j \neq i}\left(z_{j t+1}^{\prime}-\bar{z}_{j t+1}\right) \\
= & \frac{\sigma_{a}^{2}\left(\sigma_{a}^{2}+\sigma_{\varepsilon}^{2}\right)}{\left(\sigma_{a}^{2}+\sigma_{\varepsilon}^{2}\right)\left(\sigma_{a}^{2}+\sigma_{\varepsilon}^{2}+M \sigma_{f}^{2}\right)}\left(f_{t+1}-\bar{f}\right) \\
+ & \frac{\sigma_{a}^{2}\left(\sigma_{a}^{2}+\sigma_{\varepsilon}^{2}+(M-1) \sigma_{f}^{2}\right)}{\left(\sigma_{a}^{2}+\sigma_{\varepsilon}^{2}\right)\left(\sigma_{a}^{2}+\sigma_{\varepsilon}^{2}+M \sigma_{f}^{2}\right)}\left[\left(a_{i t+1}-\bar{a}_{i}\right)+\varepsilon_{i t+1}+\left(1-\alpha_{i}\right)\left(\ln G_{i t+1}-\ln G_{i t+1}^{*}+\varphi_{i t+1}-\varphi_{i t+1}^{*}\right)\right] \\
- & \frac{\sigma_{a}^{2} \sigma_{f}^{2}}{\left(\sigma_{a}^{2}+\sigma_{\varepsilon}^{2}\right)\left(\sigma_{a}^{2}+\sigma_{\varepsilon}^{2}+M \sigma_{f}^{2}\right)} \sum_{j \neq i}\left[\left(a_{j t+1}-\bar{a}_{j}\right)+\varepsilon_{j t+1}+\left(1-\alpha_{j}\right)\left(\ln G_{j t+1}-\ln G_{j t+1}^{*}+\varphi_{j t+1}-\varphi_{j t+1}^{*}\right)\right] .
\end{aligned}
$$

Like before, the central government's perception of the governor's ability $\hat{a}_{i t+1}-\bar{a}_{i}$ is tied to his output overreporting $\varphi_{i t+1}-\varphi_{i t+1}^{*}$, even though the central government anticipates he will inflate by $\varphi_{i t+1}=\varphi_{i t+1}^{*}$.

I further expand the tax system by assuming that the local government needs to transfer part of its tax revenue to the central government at a rate of $\tau_{c}<\tau$ based on the reported output level $Y_{i t+1}^{\prime}$. In other words, while the local government collects a tax of $\tau Y_{i t+1}$ based on the actual output, it has to transfer a greater fraction of the tax revenue to the central government if it chooses to overreport the output. Then, the residual tax revenue for the local government is

$$
\begin{aligned}
T_{i t+1} & =\tau Y_{i t+1}-\tau_{c} Y_{i t+1}^{\prime} \\
& =\tau Y_{i t+1}\left(1-\frac{\tau_{c}}{\tau} e^{\varphi_{i t+1}}\right) .
\end{aligned}
$$

A higher overreporting $\varphi_{i t+1}$ thus reduces the local budget for the following period. 
I now revisit the governor's Bellman equation:

$V\left(G_{i t}, T_{i t}\right)=\max _{G_{i t+1}, \varphi_{i t+1}} E_{t}\left[\gamma \ln \left(\left(1-\delta_{G}\right) G_{i t}+T_{i t}-G_{i t+1}\right)+\chi_{i}\left(\hat{a}_{i t+1}-\bar{a}_{i}\right)+\beta V\left(G_{i t+1}, T_{i t+1}\right)\right]$,

where I reformulate the value function as a function of $G_{i t}$ and $T_{i t}$, rather than a function of the total budget $W_{i t}$. This is because overreporting makes $W_{i t}$ insufficient to capture the state of the regional economy. The relevant terms in the governor's objective for choosing $G_{i t+1}$ and $\varphi_{i t+1}$ on the right-hand side of the Bellman equation are

$$
\begin{aligned}
\max _{G_{i t+1}, \varphi_{i t+1}} \gamma \ln \left(\left(1-\delta_{G}\right) G_{i t}\right. & \left.+T_{i t}-G_{i t+1}\right)+\kappa_{i} \ln \left(G_{i t+1}\right)+\kappa_{i}\left(\varphi_{i t+1}-\varphi_{i t+1}^{*}\right) \\
& +\beta E_{t}\left[V\left(G_{i t+1}, \tau Y_{i t+1}\left(1-\frac{\tau_{c}}{\tau} e^{\varphi_{i t+1}}\right)\right)\right] .
\end{aligned}
$$

The term $\kappa_{i}\left(\varphi_{i t+1}-\varphi_{i t+1}^{*}\right)$, with $\kappa_{i}$ given in (12), captures the governor's incentive to boost his career by overreporting the output, while the last term $\beta E_{t}\left[V\left(G_{i t+1}, \tau Y_{i t+1}\left(1-\frac{\tau_{c}}{\tau} e^{\varphi_{i t+1}}\right)\right)\right]$ contains the cost of leaving a smaller fiscal budget for the next period.

By solving this Bellman equation, the next proposition confirms that the governor's career concern indeed leads to overreporting of the local output, and such overreporting increases with his career incentive $\kappa_{i}$ and decreases with the central government tax rate $\tau_{c}$.

Proposition 4 The governor's output overreporting is given by the following equation:

$\varphi_{i t+1}=\ln \frac{(1-\beta) \kappa_{i}}{\beta \tau_{c}\left(\kappa_{i}+\gamma\right)}-\ln \left\{\left(\frac{\alpha_{i}}{R}\right)^{\alpha_{i} /\left(1-\alpha_{i}\right)} E_{t}\left[\frac{A_{i t+1}^{1 /\left(1-\alpha_{i}\right)}}{1-\delta_{G}+\tau\left(1-\frac{\tau_{c}}{\tau} e^{\varphi_{i t+1}}\right)\left(\frac{\alpha_{i}}{R}\right)^{\alpha_{i} /\left(1-\alpha_{i}\right)} A_{i t+1}^{1 /\left(1-\alpha_{i}\right)}}\right]\right\}$,

which has a unique root between 0 and $\ln \left(\tau / \tau_{c}\right)$ under the conditions (21) and (22) listed in the Appendix. This root is increasing with $\kappa_{i}$ and decreasing with $\tau_{c}$.

This mechanism for regional governors to overreport output is similar in spirit to that for earnings manipulation by publicly listed firms, e.g., Stein (1989). As firm managers have incentives to boost their stock prices, the signal jamming mechanism causes them to overreport firm earnings, despite that investors rationally anticipate such overreporting and deduct it from stock valuation. By confirming this mechanism, Proposition 4 suggests that the lack of reliable economic statistics in China may not be random noise and instead could be a systematic problem associated with China's government bureaucracy. 


\section{Excessive Leverage}

So far I have restricted regional governments from using any debt to leverage their fiscal budgets. This assumption is realistic for China in the period before 2008, as the central government had strict rules against subnational governments' raising debt without its explicit approval. However, the situation changed substantially after 2008, when the global financial crisis prompted China to implement a massive economic stimulus of four trillion RMB. As the stimulus was mostly financed by fiscal budgets of local governments (rather than that of the central government), and the stimulus required much more financing than what local governments could afford, the central government allowed local governments to establish the "local government financing vehicle" (LGFV), which used explicit or implicit guarantees from local governments to obtain bank loans to fund the stimulus projects, e.g., Bai, Hsieh and Song (2016). After the stimulus program ended in 2010, the central government instructed banks to discontinue lending to local governments. Facing pressure to roll over their maturing loans, local governments moved their debt financing into shadow banking, as analyzed in detail by Chen, He and Liu (2017), leading to even higher leverage. Zhang and Barnett (2014) provide an estimate that debt financing (in the forms of both bank loans and shadow banking debt) contributed to about two-thirds of infrastructure investment in China in 20082012 .

Debt gives a governor a greater capacity to invest in local infrastructure and thus may exacerbate his short-termist behavior induced by career concerns. To address this issue, I further extend the model setting. Specifically, I anchor on the setting from Section 2 (without output overreporting and tax transfer to the central government), and allow each regional government to use debt to finance its infrastructure investment and spending. Specifically, I assume that it can issue debt at a constant interest rate $R$. Then, its budget in period $t$ is its tax revenue from the previous period $\tau Y_{i t}$ plus the stock of infrastructure $\left(1-\delta_{G}\right) G_{i t}$ minus its debt due $R D_{i t-1}$ :

$$
W_{i t}=\tau Y_{i t}+\left(1-\delta_{G}\right) G_{i t}-R D_{i t-1}
$$

The governor can take new debt $D_{t}$, in addition to $W_{i t}$, to fund the next-period infrastructure $G_{i t+1}$ and government consumption $E_{i t}^{G}$ :

$$
G_{i t+1}+E_{i t}^{G}=W_{i t}+D_{i t} .
$$


I keep the Bellman equation in (11) but give the governor the additional debt choice in each period:

$$
\begin{gathered}
V\left(W_{i t}\right)=\max _{G_{i t+1}, D_{i t}} E_{t}\left[\gamma \ln E_{i t}^{G}+\chi_{i}\left(\hat{a}_{i t+1}-\bar{a}_{i}\right)+\beta V\left(\tau Y_{i t+1}+\left(1-\delta_{G}\right) G_{i t+1}-R D_{i t}\right)\right] \\
=\max _{G_{i t+1}, D_{i t}} \gamma \ln \left(W_{i t}+D_{i t}-G_{i t+1}\right)+\kappa_{i}\left(\ln G_{i t+1}-\ln G_{i t+1}^{*}\right) \\
\quad+\beta E_{t}\left[V\left(\tau Y_{i t+1}+\left(1-\delta_{G}\right) G_{i t+1}-R D_{i t}\right)\right]
\end{gathered}
$$

It shall be clear that $W_{i t}$ is sufficient to capture the state of the regional economy at time $t$, despite the use of debt. To facilitate our analysis, I scale the local government's infrastructure in each period by its budget:

$$
g_{i t+1}=\frac{G_{i t+1}}{W_{i t}}
$$

and debt level by its infrastructure level:

$$
d_{i t}=\frac{D_{i t}}{G_{i t+1}}
$$

$d_{i t}$ can be directly interpreted as the fraction of infrastructure financed by debt. As I formally derive in the Appendix, debt allows the governor to take on a higher level of infrastructure relative to its current-period budget:

$$
g_{i t+1}=\frac{\beta \gamma+\kappa_{i}}{\gamma+\kappa_{i}} \frac{1}{\left(1-d_{i t}\right)}
$$

A certain level of debt is socially beneficial as it allows the regional government to expand its budget to fully take advantage of high productivity in the current period. However, the governor's career concerns may induce excessive use of debt to finance overinvestment at the expense of a higher debt payment and thus a smaller budget in the next period. To systematically examine this issue, I also examine the debt choice of a social planner who aims to maximize the welfare of both the government and the households. Following the setting in Section 1.3, the planner's budget at time $t$ is

$$
W_{i t}^{\text {planner }}=Y_{i t}+\left(1-\delta_{G}\right) G_{i t}-R D_{i t-1},
$$

which also includes repayment of the local government debt from the previous period. The planner can also use new debt to boost its current period budget:

$$
C_{i t}^{t}+C_{i t}^{t-1}+E_{i t}^{G}+G_{i t+1}=W_{i t}^{\text {planner }}+D_{i t}
$$


to finance infrastucture investment $G_{i t+1}$, together with the consumption of the two generations of households $C_{i t}^{t}$ and $C_{i t}^{t-1}$ and the government consumption $E_{i t}^{G}$. Then, the planner's Bellman equation is given by

$$
V\left(W_{i t}^{\text {planner }}\right)=\max _{G_{i t+1}, C_{i t}^{t}, C_{i t}^{t-1}, E_{i t}^{G}, D_{i t}} E_{t}\left[\ln \left(C_{i t}^{t}\right)+\ln \left(C_{i t}^{t-1}\right)+\gamma \ln E_{i t}^{G}+\beta V\left(W_{i t+1}^{\text {planner }}\right)\right] .
$$

I directly solve the Bellman equation of both the governor in (13) and the planner in (14). Interestingly, their debt choices are determined by a maximization problem with the same structure except different coefficients, as summarized in the following proposition:

Proposition 5 Both the governor and the social planner would choose a debt level of $d_{i t}=$ $D_{i t} / G_{i t+1}$ in the interval $\left[0,\left(1-\delta_{G}\right) / R\right]$, based on the following maximization problem:

$$
\max _{d_{i t}} \Psi \ln \left(\frac{1}{1-d_{i t}}\right)+E_{t}\left[\ln \left(\tau\left(\frac{\alpha_{i}}{R}\right)^{\alpha_{i} /\left(1-\alpha_{i}\right)} A_{i t+1}^{1 /\left(1-\alpha_{i}\right)}+\left(1-\delta_{G}\right)-R d_{i t}\right)\right],
$$

where the coefficient $\Psi$ is 1 for the planner's choice and $\frac{1-\beta}{\beta} \frac{\kappa_{i}}{\gamma+\kappa_{i}}+1$ for the governor's choice. If

$$
E_{t}\left[\frac{R}{\tau\left(\frac{\alpha_{i}}{R}\right)^{\alpha_{i} /\left(1-\alpha_{i}\right)} A_{i t+1}^{1 /\left(1-\alpha_{i}\right)}+\left(1-\delta_{G}\right)}\right]<\Psi<E_{t}\left[\frac{R+\delta_{G}-1}{\tau\left(\frac{\alpha_{i}}{R}\right)^{\alpha_{i} /\left(1-\alpha_{i}\right)} A_{i t+1}^{1 /\left(1-\alpha_{i}\right)}}\right],
$$

there is an interior debt choice. Furthermore, the governor's debt choice is always higher than the planner's and the governor's debt choice is increasing with his career incentive parameter $\kappa_{i}$.

This proposition shows that career concerns indeed lead the governor to take on excessive debt, i.e., a debt level higher than the level chosen by the social planner. In choosing the debt level, both the governor and the planner face the same intertemporal tradeoff- a higher debt level boosts the current period's output, as reflected by the first term in (15), at the expense of a higher debt payment in the following period, as reflected by the second term in (15). The career concern causes the government to assign a greater weight to the first term, leading to a higher debt choice.

To further illustrate the governor's debt choice, Figure 1 depicts the debt choices of the governor and the planner under a set of baseline parameter values:

$$
\begin{aligned}
& \tau=0.2, \alpha=1 / 3, R=1.1, \delta_{G}=0.05, \beta=0.9, \gamma=1 \\
& \bar{f}=\bar{a}=0.05, \sigma_{f}=0.4, \sigma_{a}=0.4, \sigma_{\varepsilon}=0.2, \kappa_{i}=1
\end{aligned}
$$



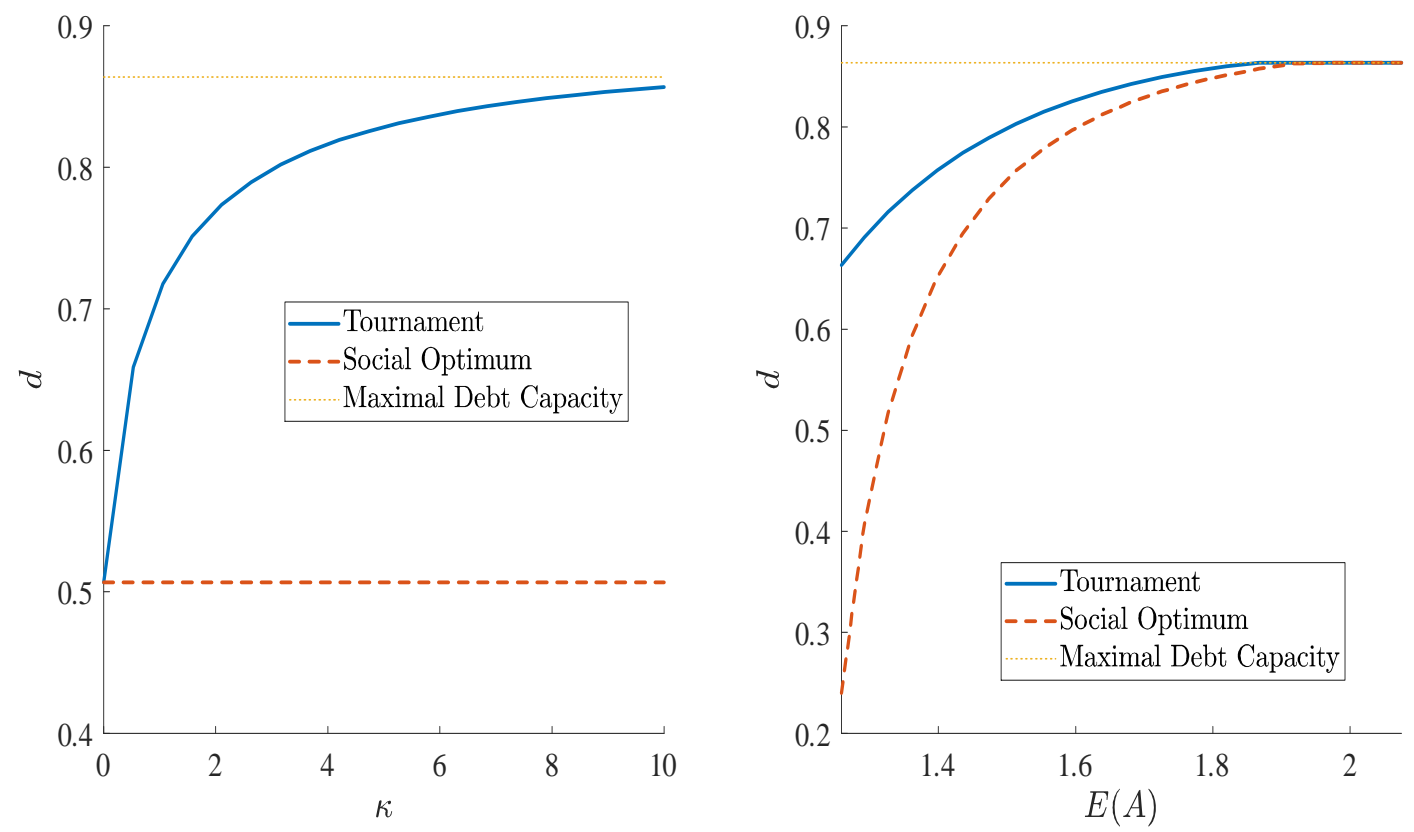

Figure 1: Leverage with Career Incentives and Expected Growth

The left panel depicts $d_{i t}$ by varying $\kappa_{i}$ between 0 and 10 . The governor's debt choice coincides with the planner's choice when $\kappa_{i}=0$. As the governor's career incentives rise with $\kappa_{i}$, his debt choice also rises with $\kappa_{i}$. The right panel depicts the debt choices of the governor and the planner by varying the expected productivity growth $E\left(A_{i}\right)$. As expected, both debt choices are increasing with $E\left(A_{i}\right)$, with the governor's debt choice always higher than the planner's. Taken together, this section describes a mechanism for the local governor's career concern to lead to overinvestment in infrastructure by using excessive leverage.

\section{$5 \quad$ Leverage Spillover}

Policy innovations and financial innovations can complicate the agency problem between the central and local governments. In this section, I analyze a novel channel through which innovations can cause short-termist leverage choices by one governor to spill over to other governors.

The discussion of local governors' career concerns so far builds on the premise that the central government fully anticipates each regional governor's short-termist behaviors (such as overreporting and excessive leverage) with rational expectations and, consequently, is able 
to perfectly filter the effect of any short-termist behavior of one governor on the relative performance evaluation of other governors. This means that short-termist behaviors do not spread across governors. Innovations may prevent the central government from fully anticipating the short-termist behaviors of local governments. First, as part of the key gradualistic approach adopted by China to reform its economy over the past 40 years, the central government encouraged local officials to experiment with policy reforms and innovations at the regional level and also encouraged local officials to follow and imitate promising policy initiatives of other regions. When a new policy initiative emerges, the central government often takes a passive mode of simply observing its effects before eventually determining whether to endorse or terminate it. $\mathrm{Xu}$ (2011) gives an extensive review of this reform approach and argues that it has played an important role in China's institutional development. This reform approach implies that the central government is, by design, slow to catch up with the policy innovations of local governments.

Second, financial innovations further complicate the central government's learn process of new strategies or new games created by local governments. This is because financial innovations provide new instruments and new arrangements for local governments to strategically hide or reveal part of their financial transactions and fiscal conditions to the central government. For example, various shadow banking products, such as wealth management products, allow banks to move regular bank loans made to local government financing vehicles off their own balance sheets. By doing so, banks are able to make at least some of these loans off the radar of the central government. While it is easy for the central government to anticipate the incentives of local governments to pursue short-termist behaviors, the lack of transparent statistics makes it difficult for the central government to figure out the specific form and magnitude of such behaviors, when they are hidden behind complicated financial arrangements.

If the central government does not fully anticipate the debt and investment levels taken by each local government, the tournament between the regional governors may take a different form because short-termist behaviors by one governor can also motivate other governors to pursue short-termist strategies, which in turn may feed back to the initial governor, leading to a rat race among the governors. To formally address this issue, I suppose that the central government faces a delay in updating its anticipation of each local governor's investment: 
$G_{i t}^{*}=G_{i t-1}$, which is similar in nature to adaptive expectations. ${ }^{4}$ Following the central government's learning of governor $i$ in (10),

$$
\begin{aligned}
\hat{a}_{i t}-\bar{a}_{i}= & \lambda\left[\left(f_{t}-\bar{f}\right)+\left(a_{i t}-\bar{a}_{i}\right)+\varepsilon_{i t}+\left(1-\alpha_{i}\right)\left(\ln G_{i t}-\ln G_{i t-1}\right)\right] \\
& -\lambda^{\prime} \sum_{j \neq i}\left[\left(f_{t}-\bar{f}\right)+\left(a_{j t}-\bar{a}_{j}\right)+\varepsilon_{j t}+\left(1-\alpha_{j}\right)\left(\ln G_{j t}-\ln G_{j t-1}\right)\right],
\end{aligned}
$$

where

$$
\lambda=\frac{\sigma_{a}^{2}\left(\sigma_{a}^{2}+\sigma_{\varepsilon}^{2}+(M-1) \sigma_{f}^{2}\right)}{\left(\sigma_{a}^{2}+\sigma_{\varepsilon}^{2}\right)\left(\sigma_{a}^{2}+\sigma_{\varepsilon}^{2}+M \sigma_{f}^{2}\right)} \text { and } \lambda^{\prime}=\frac{\sigma_{a}^{2} \sigma_{f}^{2}}{\left(\sigma_{a}^{2}+\sigma_{\varepsilon}^{2}\right)\left(\sigma_{a}^{2}+\sigma_{\varepsilon}^{2}+M \sigma_{f}^{2}\right)} .
$$

An immediate consequence of the central government's adaptive expectations is that each local governor's career concerns are no longer immune from the investment and leverage choices of other governors, as reflected by the summation term involving $G_{j t}$ in this formula.

In practice, the central government often directly compares the performance of a governor with another governor in a region with similar economic conditions. Building on the linear career incentive specified in (13), I also add another quadratic term to the governor's career incentive:

$$
V\left(W_{i t}\right)=\max _{G_{i t+1}, D_{i t}} E_{t}\left[\gamma \ln \left(E_{i t}^{G}\right)+\kappa_{i}\left(\hat{a}_{i t+1}-\hat{a}_{i^{\prime} t+1}\right)-\phi_{i}\left(\hat{a}_{i t+1}-\hat{a}_{i^{\prime} t+1}\right)^{2}+\beta V\left(W_{i t+1}\right)\right]
$$

where $i^{\prime}$ is another governor paired with $i$. This quadratic term gives an increasing incentive for governor $i$ to catch up with the other governor. As there are a large number of other governors, I suppose that $i^{\prime}$ is chosen to have the same economic conditions: $G_{i^{\prime} t}=G_{i t}$ and $W_{i^{\prime} t}=W_{i t}$. This pairing allows me to maintain simplicity of the derivation without any loss of generality. I also make the setting symmetric so that $\bar{a}_{i}=\bar{a}_{j}=\bar{a}$ and $\alpha_{i}=\alpha_{j}=\alpha$. Then, it follows that

$$
\hat{a}_{i t+1}-\hat{a}_{i^{\prime} t+1}=\left(\lambda+\lambda^{\prime}\right)\left[a_{i t+1}-a_{i^{\prime} t+1}+\varepsilon_{i t+1}-\varepsilon_{i^{\prime} t+1}+(1-\alpha)\left(\ln G_{i t+1}-\ln G_{i^{\prime} t+1}\right)\right] .
$$

Consequently,

$$
E_{t}\left[\kappa_{i}\left(\hat{a}_{i t+1}-\hat{a}_{i^{\prime} t+1}\right)\right]=\kappa_{i}\left(\lambda+\lambda^{\prime}\right)(1-\alpha)\left(\ln G_{i t+1}-\ln G_{i^{\prime} t+1}\right),
$$

\footnotetext{
${ }^{4}$ The specific form of how $G_{i t}^{*}$ is updated is not particularly important. As long as it is delayed and $G_{i t}^{*} \neq G_{i t}$, the investment and leverage choices of one governor would interfere the relative performance evaluation of other governors.
} 
and

$$
E_{t}\left[\phi_{i}\left(\hat{a}_{i t+1}-\hat{a}_{i^{\prime} t+1}\right)^{2}\right]=\phi_{i}\left(\lambda+\lambda^{\prime}\right)^{2}(1-\alpha)^{2}\left(\ln G_{i t+1}-\ln G_{i^{\prime} t+1}\right)^{2}+\text { const } .
$$

These two terms reveal that governor $i$ 's career concerns are affected not only by his own infrastructure investment $G_{i t+1}$ but also by the investment of his paired governor $i^{\prime}$.

I again rescale each governor's two choice variables as

$$
g_{i t+1}=\frac{G_{i t+1}}{W_{i t}} \text { and } d_{i t}=\frac{D_{i t}}{G_{i t+1}} .
$$

The following proposition summarizes the equilibrium between the two paired governors' choices.

Proposition 6 Given the investment choice $g_{i^{\prime} t+1}$ of governor $i^{\prime}$, the investment choice $g_{i t+1}$ of governor $i$ is determined by the unique positive root of the following equation:

$$
\frac{1}{\left(1-d_{i t}\right) g_{i t+1}}=1+\frac{\gamma}{\frac{\beta \gamma}{1-\beta}+\kappa_{i}\left(\lambda+\lambda^{\prime}\right)(1-\alpha)-\phi_{i}\left(\lambda+\lambda^{\prime}\right)^{2}(1-\alpha)^{2}\left(\ln g_{i t+1}-\ln g_{i^{\prime} t+1}\right)},
$$

which implies $g_{i t+1}$ as an increasing function of $g_{i^{\prime} t+1}$ and $d_{i t}$. Governor $i$ 's leverage choice $d_{i t}$ is then given by the following maximization problem:

$$
\begin{aligned}
\max _{d_{i t}} \gamma & \ln \left[1-\left(1-d_{i t}\right) g_{i t+1}\right]+\kappa_{i}\left(\lambda+\lambda^{\prime}\right)(1-\alpha)\left(\ln g_{i t+1}-\ln g_{i^{\prime} t+1}\right) \\
& -\phi_{i}\left(\lambda+\lambda^{\prime}\right)^{2}(1-\alpha)^{2}\left(\ln g_{i t+1}-\ln g_{i^{\prime} t+1}\right)^{2} \\
& +\frac{\beta \gamma}{1-\beta}\left[\ln g_{i t+1}+E_{t}\left[\ln \left(\tau\left(\frac{\alpha_{i}}{R}\right)^{\frac{\alpha_{i}}{1-\alpha_{i}}} A_{i t+1}^{\frac{1}{1-\alpha_{i}}}+\left(1-\delta_{G}\right)-R d_{i t}\right)\right]\right],
\end{aligned}
$$

which determines $d_{i t}=d_{i}\left(g_{i^{\prime} t+1}\right)$, and thus governor $i$ 's investment response to governor $i^{\prime}$ $i s$

$$
g_{i t+1}=g_{i}\left(g_{i^{\prime} t+1}\right)
$$

Similarly, governor $i^{\prime}$ 's investment choice $g_{i^{\prime} t+1}$ is an increasing function of $g_{i t+1}$ and $d_{i^{\prime} t}$, and leverage choice is a function $d_{i^{\prime} t}=d_{i^{\prime}}\left(g_{i t+1}\right)$, which in turn determines governor $i^{\prime}$ 's investment response to governor $i$ :

$$
g_{i^{\prime} t+1}=g_{i^{\prime}}\left(g_{i t+1}\right)
$$

Equations (17) and (18) jointly determine the equilibrium choices of the two governors. 

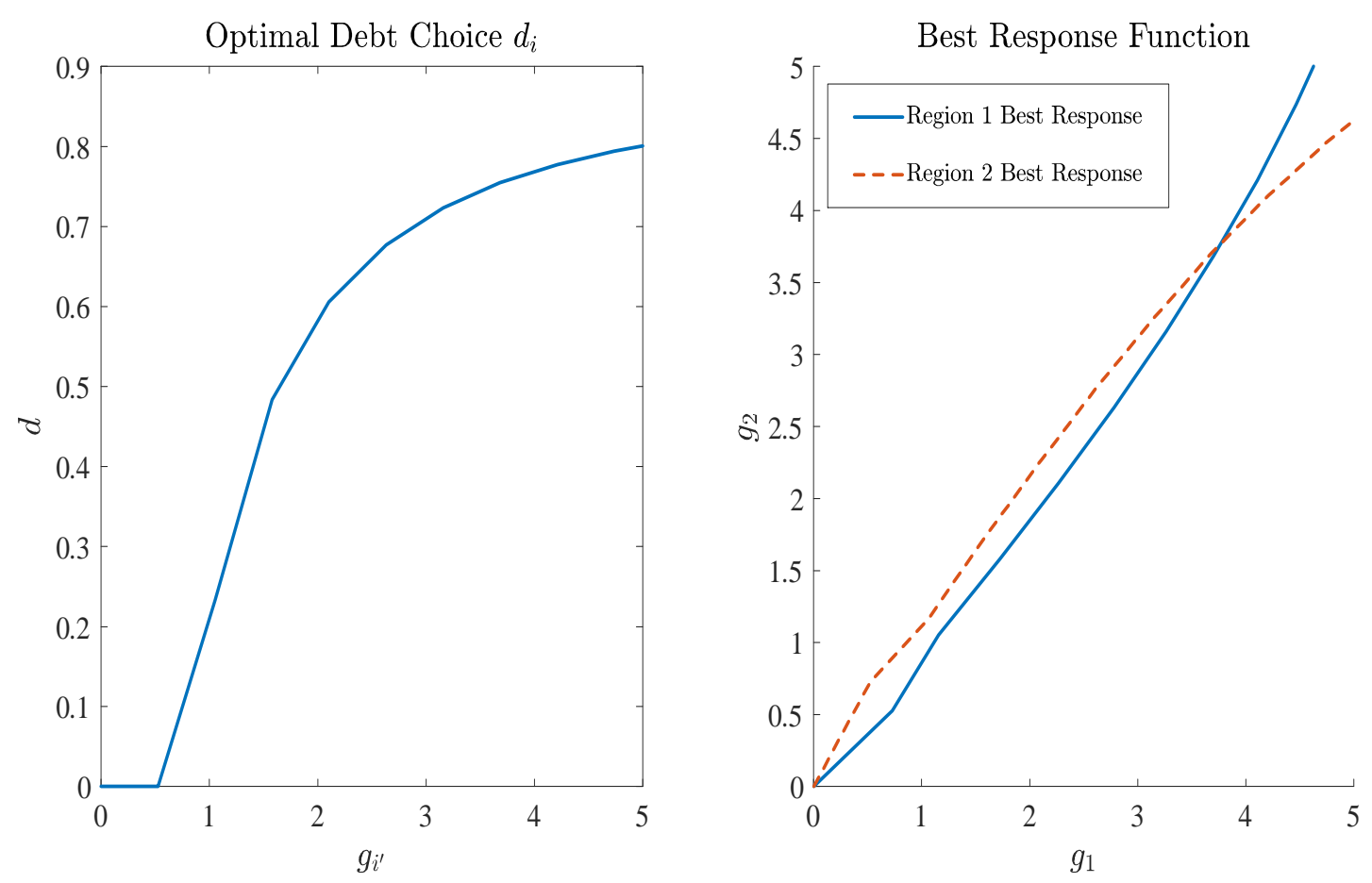

Figure 2: Equilibrium Debt and Investment Choices

Proposition 6 shows that the two governors' investment and debt choices are entangled. To illustrate their interactions, I use a numerical example based on the following parameter values:

$$
\begin{aligned}
& \tau=0.2, \alpha=1 / 3, R=1.1, \delta_{G}=0.05, \beta=0.9, \gamma=1, \\
& \bar{f}=\bar{a}=0.05, \sigma_{f}=1, \sigma_{a}=1, \sigma_{\varepsilon}=0.5 .
\end{aligned}
$$

In addition, I choose the following incentive parameters for the two governors, denoted as 1 and 2:

$$
\kappa_{1}=\kappa_{2}=2, \phi_{1}=\phi_{2}=40 .
$$

Figure 2 illustrates the equilibrium. Because of the symmetric parameters chosen for the two governors, they make symmetric investment and debt choices. The left panel depicts each governor's debt choice $d_{i}$ as a function of the other governor's investment choice $g_{i^{\prime}}$. When $g_{i^{\prime}}$ is small, $d_{i}$ is zero. As $g_{i^{\prime}}$ rises, governor $i$ chooses a higher leverage $d_{i}$ to finance greater infrastructure investment in his region. The right panel depicts the two governors' investment choices with respect to each other. The dashed line represents the best investment response $g_{2}$ of governor 2 to governor 1's investment $g_{1}$, while the solid line represents the best 


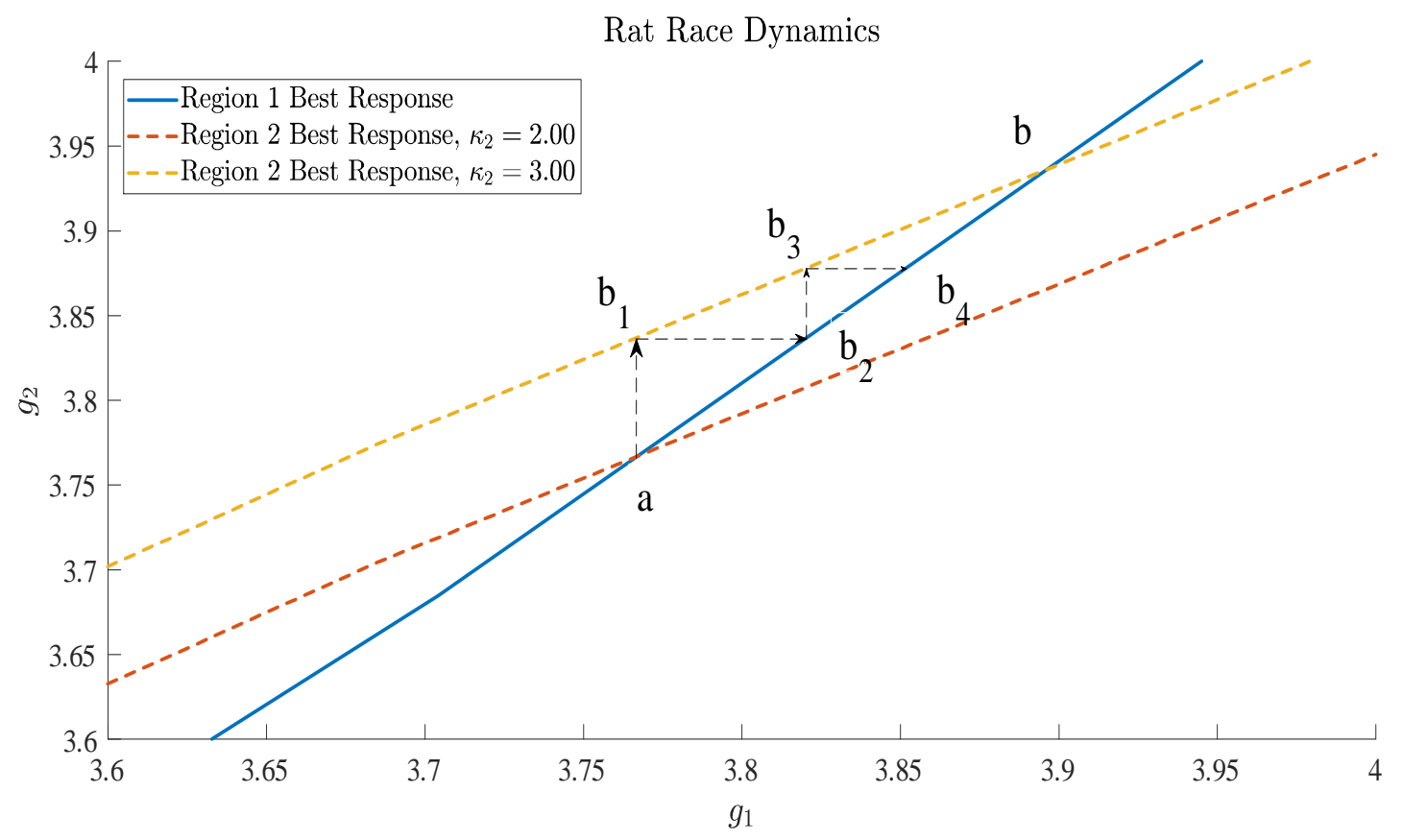

Figure 3: Rat-Race Dynamics

investment response $g_{1}$ of governor 1 to governor 2's investment $g_{2}$. Both of these investment response functions are increasing. The equlibrium lies at the intersection of these two lines.

To further highlight the interactions between the two governors' investment choices, I increase the incentive parameter $\kappa_{2}$ of governor 2 from the initial value of 2 to 3 . Figure 3 illustrates the changes in the equilibrium by plotting the investment response curves of both governors 1 and 2. Point $a$ in the plot is the initial equilibrium with $g_{1}=g_{2}=3.77$. As $\kappa_{2}$ rises from 2 to 3, governor 2 becomes more aggressive in his investment and debt choices, and his best response curve, shown by the dashed line, moves up. If governor 1's investment choice $g_{1}$ is kept at the initial value, governor 2's investment choice will move up to point $b_{1}$, which is accompanied by a corresponding increase in his debt choice not shown in the figure. However, with $g_{2}$ increased, governor 1 would also respond to increase his investment to a level given by point $b_{2}$, which in turn stimulates governor 2 to increase his investment level further to $b_{3}$, and so on and so forth. This rat-race dynamic would eventually converge and drive the equilibrium to point $b$, which has a substantially larger investment increase for governor 2 than his initial increase if governor 1's investment choice stays unchanged. Through this rat race, the change in the career incentives of governor 2 also leads to a substantial increase in the investment choice of governor 1. 


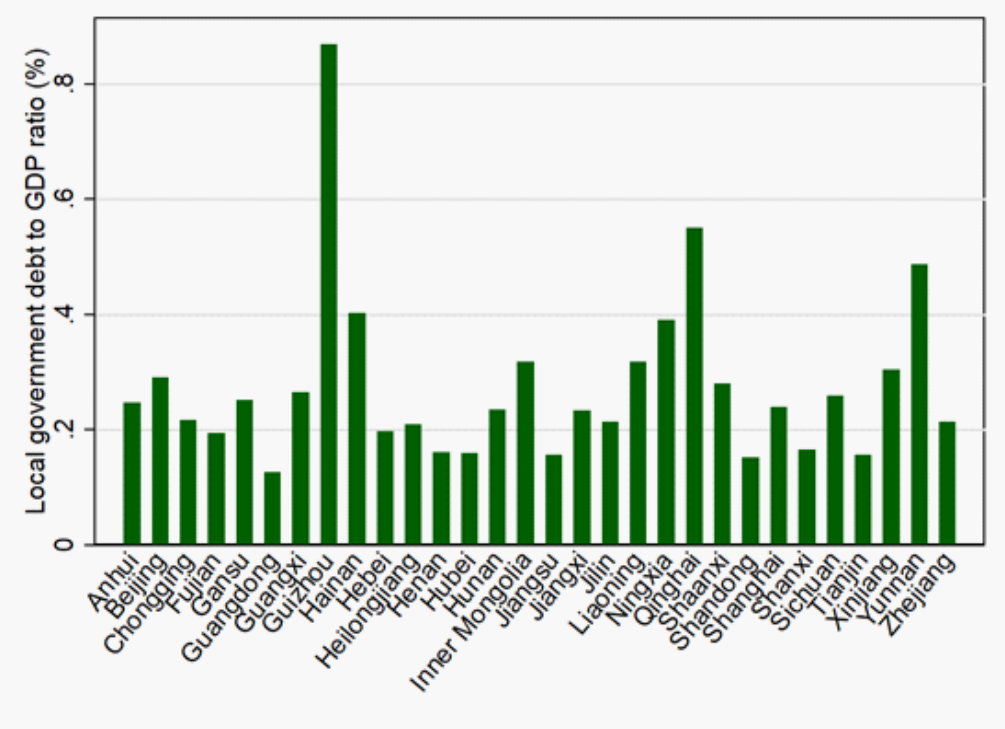

Figure 4: Local government debt to GDP ratio in 2015

\section{Discussion}

In this section, I summarize several stylized facts about local government leverage and GDP overreporting across different provinces in China to show that they lend support to the Mandarin model. A basic insight of the model is that career concerns lead local governors to overinvest by using excessive leverage, which implies a negative correlation between return to capital and local government leverage across regions. Furthermore, as career concerns lead each local governor to not only use excessive leverage but also overreport regional output, one would also expect a positive correlation between local government leverage and overreporting of local output. I organize our discussions around these two key implications.

Local government leverage As discussed earlier, the post-crisis stimulus led to a leverage boom among local governments in China. Because local governments used LGFV to raise debt from both banks and shadow banking, their debts were largely nontransparent to the central government and the public. Based on the data released by the Ministry of Finance (MoF) in 2015 (several years after the post-crisis stimulus program had ended) from its national audit of the leverage of local governments, Figure 4 depicts the local government debt-to-GDP ratio for all provinces (excluding Tibet due to its special economic status). The average debt-to-GDP ratio is 27.5 percent. There is also substantial variation in this ratio, 


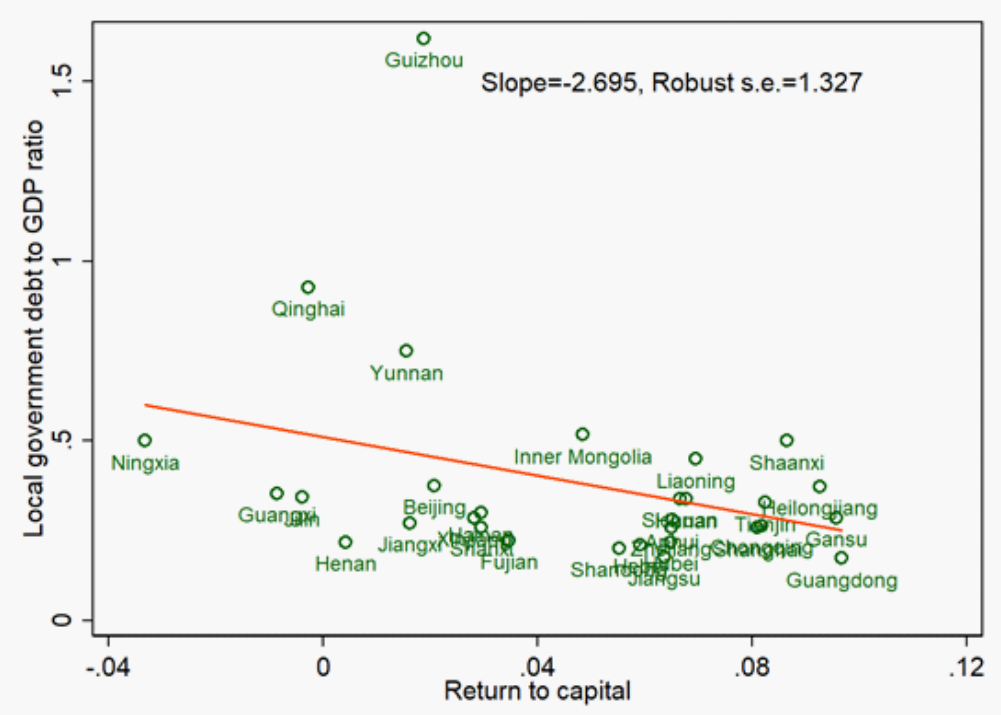

Figure 5: Local government debt-to-GDP ratio versus return to capital

with some provinces in western China, such as Guizhou and Qinghai, having a leverage ratio of over $50 \%$.

Figure 5 provides a scatter plot of the local government debt-to-GDP ratio against each province's return to capital in 2015. The latter variable is from Bai et al. (2018), which offers systematic adjustments of potential misreporting in China's provincial statistics. Consistent with the common impression, this figure shows that western provinces such as Ningxia and Qinghai tend to have higher leverage and lower return to capital, while coastal provinces such as Guangdong tend to have lower leverage and higher return to capital. Overall, local government leverage is negatively correlated with return to capital with a $t$-statistic of 2.03. This negative relationship supports the basic notion of our model that career concerns can cause local governors to overinvest by using excessive leverage.

GDP overreporting Figure 6 depicts the gap between the sum of provincial GDP (reported by provincial statistics bureaus) and the national GDP (reported by the National Bureau of Statistics) divided by the national GDP for each year in 2001-2016. Since 2004, the sum of provincial GDP has been regularly higher than the national GDP by about 5 percent. One may argue that different provinces might have double-counted output made by firms with production across provincial borders. The figure also shows the percentage of provinces reporting a GDP growth rate higher than the national GDP growth rate. In 


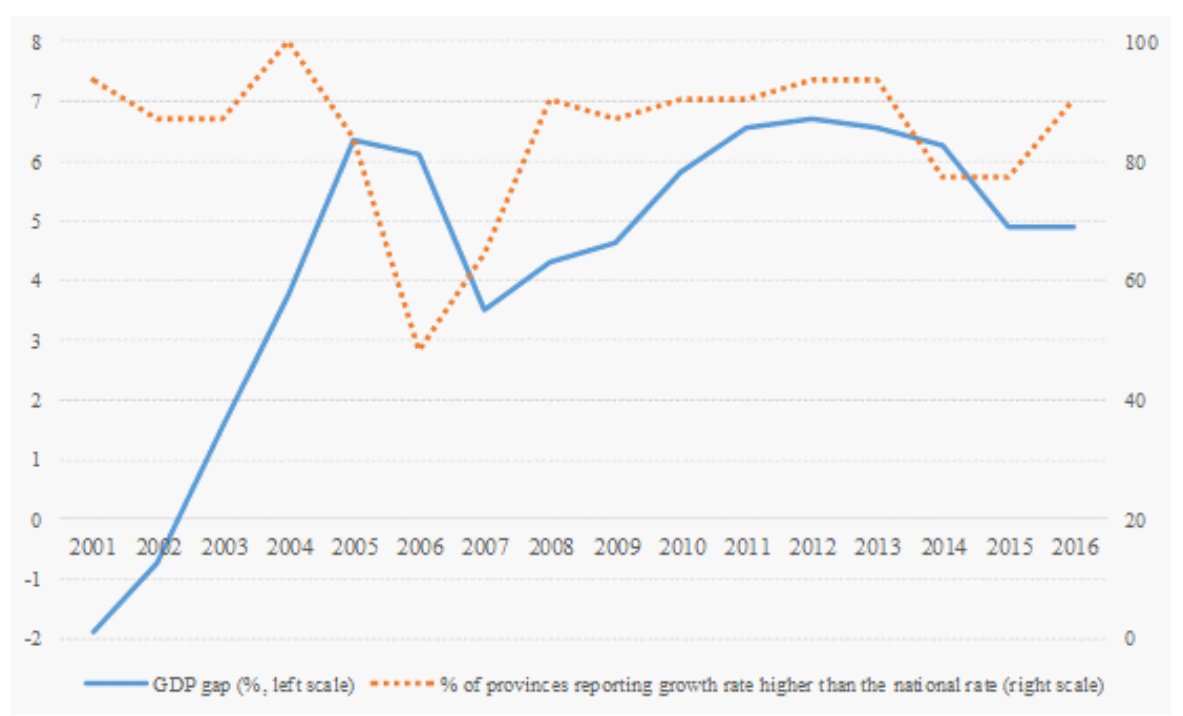

Figure 6: Provincial GDP over-reporting

a given year, over 80 percent of the provinces reported a GDP growth rate higher than the national growth rate, except in 2006 and 2007. Taken together, Figure 6 reveals a compelling pattern that provincial governments in China in aggregate overreport their GDP. ${ }^{5}$

Bai et al. (2018) provide an estimate of each province's GDP overreporting for each year after 2004. Specifically, they compare the sum of value-added of sectors as reported at the provincial level with the same sectors at the national level. They find little discrepancy in these two numbers for "above-scale" firms, but large discrepancies for below-scale firms as well as sectors in which these numbers are based on local governments' administrative data. They reestimate provincial GDP using alternative data sources, such as China Customs and microdata from national value-added tax invoices. They assume that final consumption (at both the national and provincial levels) and net exports (at the national level) are reliable. They correct provincial GDP mainly through adjusting investment data.

Based on the provincial GDP overreporting estimated by Bai et al. (2018), Figure 7 provides a scatter plot of the ratio of provincial GDP overreporting to GDP and local government debt-to-GDP ratio in 2015. Interestingly, western provinces such as Guizhou and

\footnotetext{
${ }^{5}$ Such over-reporting is not sustainable. In recent years, several provinces have publicly acknowledged their GDP over-reporting in the past so that they can reset the GDP base for better performance in the future years. In early 2017, provincial government of Jiaoning revealed in its annual report submitted to its People's Congress that it has systematically over-reported Liaoning's economic statistics in 2011-2014. In January 2018, the provincial governments of both Inner Mongolia and Tianjing also confessed that they have also inflated their economic statistics in the previous years.
} 


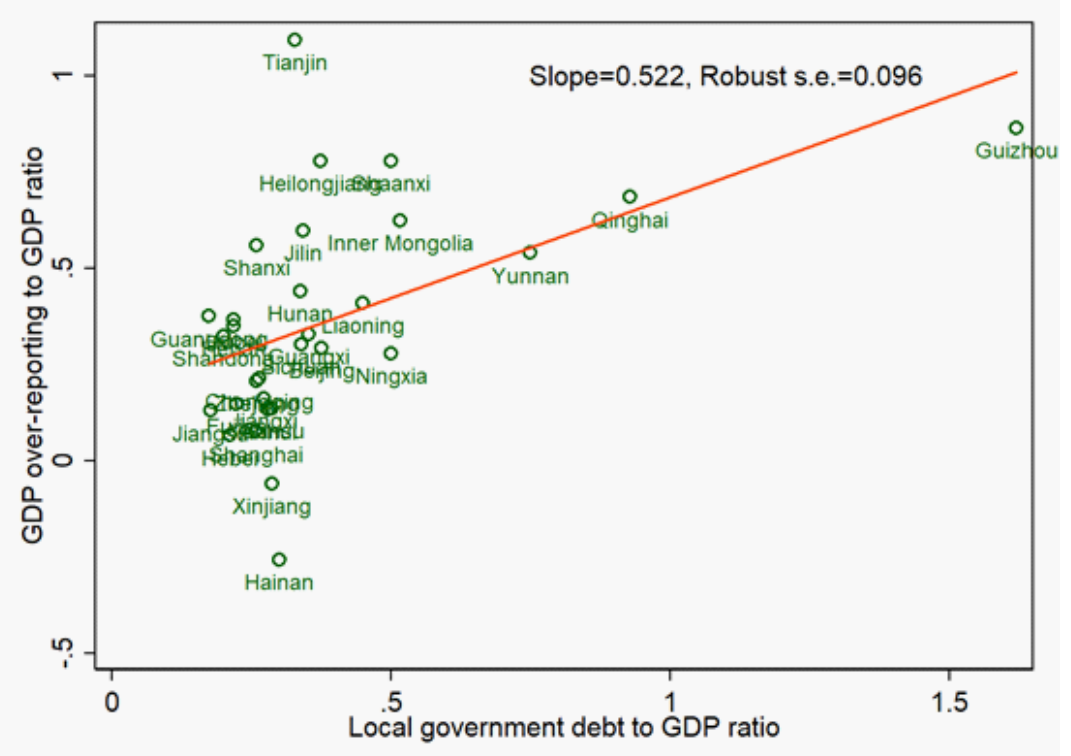

Figure 7: Provincial GDP over-reporting versus local government leverage

Qinghai again show both higher leverage and greater GDP overreporting. Overall, there is an evident positive relationship between GDP overreporting and local government leverage with a $t$-statistic of 5.4. This significant relationship supports a key prediction of our model that career concerns lead local governors to pursue excessive leverage and overreport local output.

\section{Conclusion}

This paper develops the Mandarin model of growth to capture two key features of the Chinese economy. First, the government takes a central role in driving the economy through its active investment in infrastructure. Second, agency problems in the government system generate a rich set of phenomena in the Chinese economy, including not only rapid economic growth propelled by the tournament among local governors but also short-termist behaviors of local governors, which directly affect China's economic and financial stability. 


\section{A Appendix}

\section{A.1 Proof for Proposition 1}

By substituting in the various consumption components in Bellman equation (5), I have

$$
V\left(W_{i t}\right)=\max _{G_{i t+1}} E_{t}\left[\gamma \ln \left(W_{i t}-G_{i t+1}\right)+\beta V\left(\left(1-\delta_{G}\right) G_{i t+1}+\tau Y_{i t+1}\right)\right] .
$$

I conjecture that

$$
V(W)=k_{w} \ln W+k_{0} .
$$

Then, the right hand side of Bellman equation (19) is

$$
\begin{aligned}
& \max _{G_{i t+1}} E_{t}\left[\gamma \ln \left(W_{i t}-G_{i t+1}\right)+\beta V\left(\left(1-\delta_{G}\right) G_{i t+1}+\tau\left(\frac{\alpha_{i}}{R}\right)^{\alpha_{i} /\left(1-\alpha_{i}\right)} A_{i t+1}^{1 /\left(1-\alpha_{i}\right)} G_{i t+1}\right)\right] \\
= & \max _{G_{i t+1}} E_{t}\left\{\gamma \ln \left(W_{i t}-G_{i t+1}\right)+\beta k_{w}\left[\ln G_{i t+1}+\ln \left(\left(1-\delta_{G}\right)+\tau\left(\frac{\alpha_{i}}{R}\right)^{\alpha_{i} /\left(1-\alpha_{i}\right)} A_{i t+1}^{1 /\left(1-\alpha_{i}\right)}\right)\right]+\beta k_{0}\right\} \\
= & \max _{G_{i t+1}} \gamma \ln \left(W_{i t}-G_{i t+1}\right)+\beta k_{w} \ln G_{i t+1}+\beta k_{w} E_{t}\left\{\ln \left(\left(1-\delta_{G}\right)+\tau\left(\frac{\alpha_{i}}{R}\right)^{\alpha_{i} /\left(1-\alpha_{i}\right)} A_{i t+1}^{1 /\left(1-\alpha_{i}\right)}\right)\right\}+\beta k_{0} .
\end{aligned}
$$

Then, the first-order condition gives

$$
\frac{\beta k_{w}}{G_{i t+1}}=\frac{\gamma}{W_{i t}-G_{i t+1}},
$$

which directly implies that

$$
G_{i t+1}=\frac{\beta k_{w}}{\gamma+\beta k_{w}} W_{i t}
$$

The government spending is then $\frac{\gamma}{\gamma+\beta k_{w}} W_{i t}$.

Then, the right-hand side of the Bellman equation becomes

$$
\begin{aligned}
& \gamma \ln \left(W_{i t}-G_{i t+1}\right)+\beta k_{w} \ln \left(G_{i t+1}\right)+\beta k_{w} E_{t}\left\{\ln \left(\left(1-\delta_{G}\right)+\tau\left(\frac{\alpha_{i}}{R}\right)^{\alpha_{i} /\left(1-\alpha_{i}\right)} A_{i t+1}^{1 /\left(1-\alpha_{i}\right)}\right)\right\}+\beta k_{0} \\
= & \left(\gamma+\beta k_{w}\right) \ln \left(W_{i t}\right)+\ln \left(\frac{\gamma}{\gamma+\beta k_{w}}\right)+\beta k_{w} \ln \left(\frac{\beta k_{w}}{\gamma+\beta k_{w}}\right) \\
& +\beta k_{w} E_{t}\left\{\ln \left(\left(1-\delta_{G}\right)+\tau\left(\frac{\alpha_{i}}{R}\right)^{\alpha_{i} /\left(1-\alpha_{i}\right)} A_{i t+1}^{1 /\left(1-\alpha_{i}\right)}\right)\right\}+\beta k_{0} .
\end{aligned}
$$

To equate this with the left-hand side, $k_{w} \ln W_{i}+k_{0}$, I need

$$
k_{w}=\gamma+\beta k_{w}, \Rightarrow k_{w}=\frac{\gamma}{1-\beta}
$$

and

$$
\begin{aligned}
k_{0}= & \ln \left(\frac{\gamma}{\gamma+\beta k_{w}}\right)+\beta k_{w} \ln \left(\frac{\beta k_{w}}{\gamma+\beta k_{w}}\right) \\
& +\beta k_{w} E_{t}\left\{\ln \left(\left(1-\delta_{G}\right)+\tau\left(\frac{\alpha_{i}}{R}\right)^{\alpha_{i} /\left(1-\alpha_{i}\right)} A_{i t+1}^{1 /\left(1-\alpha_{i}\right)}\right)\right\}+\beta k_{0},
\end{aligned}
$$


which gives

$$
\begin{aligned}
k_{0}= & \frac{1}{1-\beta}\left[\ln \left(\frac{\gamma}{\gamma+\beta k_{w}}\right)+\beta k_{w} \ln \left(\frac{\beta k_{w}}{\gamma+\beta k_{w}}\right)\right] \\
& +\frac{\beta}{(1-\beta)^{2}} E_{t}\left\{\ln \left(\left(1-\delta_{G}\right)+\tau\left(\frac{\alpha_{i}}{R}\right)^{\alpha_{i} /\left(1-\alpha_{i}\right)} A_{i t+1}^{1 /\left(1-\alpha_{i}\right)}\right)\right\} .
\end{aligned}
$$

Thus, $G_{i t+1}=\beta W_{i t}$.

\section{A.2 Proof of Proposition 2}

I have the following Bellman equation for the planner:

$$
V\left(W_{i t}^{\text {planner }}\right)=\max _{G_{i t+1}, C_{i t}^{t}, C_{i t}^{t-1}, E_{i t}^{G}} E_{t}\left[\ln \left(C_{i t}^{t}\right)+\ln \left(C_{i t}^{t-1}\right)+\gamma \ln E_{i t}^{G}+\beta V\left(W_{i t+1}^{\text {planner }}\right)\right]
$$

subject to

$$
C_{i t}^{t}+C_{i t}^{t-1}+E_{i t}^{G}+G_{i t+1}=W_{i t}^{\text {planner }}
$$

I again conjecture that

$$
V(W)=k_{w} \ln W+k_{0} .
$$

Then,

$$
\begin{aligned}
& V\left(W_{i t}^{\text {planner }}\right) \\
= & \max _{G_{i t+1}, C_{i t}^{t}, C_{i t}^{t-1}, E_{i t}^{G}} E_{t}\left[\ln \left(C_{i t}^{t}\right)+\ln \left(C_{i t}^{t-1}\right)+\gamma \ln E_{i t}^{G}+\beta k_{w} \ln \left(W_{i t+1}^{\text {planner }}\right)+\beta k_{0}\right] \\
= & \max _{G_{i t+1}, C_{i t}^{t}, C_{i t}^{t-1}, E_{i t}^{G}} E_{t}\left[\ln \left(C_{i t}^{t}\right)+\ln \left(C_{i t}^{t-1}\right)+\gamma \ln E_{i t}^{G}+\beta k_{w} \ln \left(Y_{i t+1}+\left(1-\delta_{G}\right) G_{i t+1}\right)+\beta k_{0}\right] \\
= & \max _{G_{i t+1}, C_{i t}^{t}, C_{i t}^{t-1}, E_{i t}^{G}} E_{t}\left[\ln \left(C_{i t}^{t}\right)+\ln \left(C_{i t}^{t-1}\right)+\gamma \ln E_{i t}^{G}+\beta k_{w} \ln \left(G_{i t+1}\right)\right. \\
& \left.\quad+\beta k_{w} \ln \left(\tau\left(\frac{\alpha_{i}}{R}\right)^{\alpha_{i} /\left(1-\alpha_{i}\right)} A_{i t+1}^{1 /\left(1-\alpha_{i}\right)}+\left(1-\delta_{G}\right)\right)+\beta k_{0}\right] .
\end{aligned}
$$

The first-order conditions with respect to $G_{i t+1}, C_{i t}^{t}, C_{i t}^{t-1}, E_{i t}^{G}$ give

$$
\frac{1}{C_{i t}^{t}}=\frac{1}{C_{i t}^{t-1}}=\frac{\gamma}{E_{i t}^{G}}=\frac{\beta k_{w}}{G_{i t+1}} .
$$

The budget constraint then implies that

$$
\begin{aligned}
C_{i t}^{t} & =C_{i t}^{t-1}=\frac{1}{2+\gamma+\beta k_{w}} W_{i t}^{\text {planner }} \\
E_{i t}^{G} & =\frac{\gamma}{2+\gamma+\beta k_{w}} W_{i t}^{\text {planner }} \\
G_{i t+1} & =\frac{\beta k_{w}}{2+\gamma+\beta k_{w}} W_{i t}^{\text {planner }} .
\end{aligned}
$$


Furthermore, by equating the coefficients of $\ln W_{i t}^{\text {planner }}$ on both sides of the Bellman equation, I have

$$
k_{w}=2+\gamma+\beta k_{w} \Rightarrow k_{w}=\frac{2+\gamma}{1-\beta} .
$$

Thus, $G_{i t+1}=\beta W_{i t}^{\text {planner }}$. The infrastructure level is determined by $\beta$ fraction of the social wealth, rather than the budget of the local government. This is because the social planner also internalizes the welfare of the households in addition to that of the government.

\section{A.3 Proof of Proposition 3}

I need to solve the following Bellman equation:

$$
\begin{aligned}
V\left(W_{i t}\right)=\max _{G_{i t+1}} \gamma \ln \left(W_{i t}-G_{i t+1}\right)+\kappa_{i} \ln G_{i t+1} & \\
& \quad+\beta E_{t}\left[V\left(\left(\left(1-\delta_{G}\right)+\tau\left(\frac{\alpha_{i}}{R}\right)^{\alpha_{i} /\left(1-\alpha_{i}\right)} A_{i t+1}^{1 /\left(1-\alpha_{i}\right)}\right) G_{i t+1}\right)\right] .
\end{aligned}
$$

I again conjecture that

$$
V(W)=k_{w} \ln W+k_{0} .
$$

Then, the governor's objective on the right-hand side becomes

$$
\begin{aligned}
\max _{G_{i t+1}} \gamma \ln \left(W_{i t}-G_{i t+1}\right)+\kappa_{i} \ln G_{i t+1}+\beta k_{w} \ln \left(G_{i t+1}\right) \\
\quad+E_{t}\left[\beta k_{w} \ln \left[\left(1-\delta_{G}\right)+\tau\left(\frac{\alpha_{i}}{R}\right)^{\alpha_{i} /\left(1-\alpha_{i}\right)} A_{i t+1}^{1 /\left(1-\alpha_{i}\right)}\right]\right]+\beta k_{0} .
\end{aligned}
$$

The first-order condition for $G_{i t+1}$ gives

$$
G_{i t+1}=\frac{\beta k_{w}+\kappa_{i}}{\gamma+\beta k_{w}+\kappa_{i}} W_{i t}
$$

Equating the two sides of the Bellman equation leads to

$$
k_{w}=\gamma+\kappa_{i}+\beta k_{w}, \Rightarrow k_{w}=\frac{\gamma+\kappa_{i}}{1-\beta} .
$$

Thus,

$$
G_{i t+1}=\left[\frac{\kappa_{i}}{\gamma+\kappa_{i}}(1-\beta)+\beta\right] W_{i t}
$$




\section{A.4 Proof of Proposition 4}

I now derive the Bellman equation:

$$
\begin{gathered}
V\left(G_{i t}, T_{i t}\right)=\max _{G_{i t+1}, \varphi_{i t+1}} \gamma \ln \left(\left(1-\delta_{G}\right) G_{i t}+T_{i t}-G_{i t+1}\right)+\kappa_{i} \ln \left(G_{i t+1}\right)+\kappa_{i}\left(\varphi_{i t+1}-\varphi_{i t+1}^{*}\right) \\
+\beta E_{t}\left[V\left(G_{i t+1}, \tau Y_{i t+1}\left(1-\frac{\tau_{c}}{\tau} e^{\varphi_{i t+1}}\right)\right)\right]
\end{gathered}
$$

I conjecture that

$$
V(G, T)=k_{g} \ln (G)+v(T / G) .
$$

The first-order condition for $G_{i t+1}$ gives that

$$
\frac{\kappa_{i}+\beta k_{g}}{G_{i t+1}}=\frac{\gamma}{\left(1-\delta_{G}\right) G_{i t}+T_{i t}-G_{i t+1}},
$$

which directly implies that

$$
G_{i t+1}=\frac{\kappa_{i}+\beta k_{g}}{\kappa_{i}+\beta k_{g}+\gamma}\left[T_{i t}+\left(1-\delta_{G}\right) G_{i t}\right]
$$

The first order condition for $\varphi_{i t+1}$ gives that

$$
\kappa_{i}=\beta \tau_{c} e^{\varphi_{i t+1}} E_{t}\left[\frac{Y_{i t+1}}{G_{i t+1}} v^{\prime}\left(\frac{T_{i t+1}}{G_{i t+1}}\right)\right],
$$

which further implies that

$$
\varphi_{i t+1}=\ln \left[\frac{\kappa_{i}}{\beta \tau_{c} E_{t}\left[\frac{Y_{i t+1}}{G_{i t+1}} v^{\prime}\left(\frac{T_{i t+1}}{G_{i t+1}}\right)\right]}\right] .
$$

By substituting $G_{i t+1}$ back to the Bellman equation, I have

$$
\begin{aligned}
& k_{g} \ln \left(G_{i t}\right)+v\left(T_{i t} / G_{i t}\right) \\
& =\left(\kappa_{i}+\beta k_{g}\right) \ln \left(G_{i t+1}\right)+\gamma \ln \left(\left(1-\delta_{G}\right) G_{i t}+T_{i t}\right)+\gamma \ln \left(\frac{\gamma}{\kappa_{i}+\beta k_{g}+\gamma}\right) \\
& +\kappa_{i}\left(\varphi_{i t+1}-\varphi_{i t+1}^{*}\right)+\beta E_{t}\left[v\left(\tau\left(1-\frac{\tau_{c}}{\tau} e^{\varphi_{i t+1}}\right) \frac{Y_{i t+1}}{G_{i t+1}}\right)\right] \\
& =\left(\kappa_{i}+\beta k_{g}+\gamma\right) \ln \left(G_{i t}\right)+\left(\kappa_{i}+\beta k_{g}+\gamma\right) \ln \left(1-\delta_{G}+T_{i t} / G_{i t}\right) \\
& +\left(\kappa_{i}+\beta k_{g}+\gamma\right) \ln \left(\frac{\gamma}{\kappa_{i}+\beta k_{g}+\gamma}\right) \\
& -\kappa_{i} \varphi_{i t+1}^{*}+\beta E_{t}\left[v\left(\tau\left(1-\frac{\tau_{c}}{\tau} e^{\varphi_{i t+1}}\right)\left(\frac{\alpha_{i}}{R}\right)^{\alpha_{i} /\left(1-\alpha_{i}\right)} A_{i t+1}^{1 /\left(1-\alpha_{i}\right)}\right)\right] .
\end{aligned}
$$

Thus,

$$
k_{g}=\kappa_{i}+\beta k_{g}+\gamma \quad \Rightarrow \quad k_{g}=\frac{\kappa_{i}+\gamma}{1-\beta}
$$


and

$$
v\left(T_{i t} / G_{i t}\right)=\frac{\kappa_{i}+\gamma}{1-\beta} \ln \left(1-\delta_{G}+T_{i t} / G_{i t}\right)+k_{0}
$$

with

$$
\begin{aligned}
k_{0}= & \beta E_{t}\left[v\left(\tau\left(1-\frac{\tau_{c}}{\tau} e^{\varphi_{i t}}\right)\left(\frac{\alpha_{i}}{R}\right)^{\alpha_{i} /\left(1-\alpha_{i}\right)} A_{i t+1}^{1 /\left(1-\alpha_{i}\right)}\right)\right] \\
& +\left(\kappa_{i}+\beta k_{g}+\gamma\right) \ln \left(\frac{\gamma}{\kappa_{i}+\beta k_{g}+\gamma}\right)-\kappa_{i} \varphi_{i t+1}^{*} .
\end{aligned}
$$

By substituting $v$ into $\varphi_{i t+1}$, I obtain that

$$
\begin{aligned}
& \varphi_{i t+1}=\ln \left[\frac{\kappa_{i}}{\beta \tau_{c} E_{t}\left[\frac{Y_{i t+1}}{G_{i t+1}} v^{\prime}\left(\frac{T_{i t+1}}{G_{i t+1}}\right)\right]}\right] \\
& =\ln \left[\frac{(1-\beta) \kappa_{i}}{\beta \tau_{c}\left(\kappa_{i}+\gamma\right) E_{t}\left[\frac{\left(\frac{\alpha_{i}}{R}\right)^{\alpha_{i} /\left(1-\alpha_{i}\right)} A_{i t+1}^{1 /\left(1-\alpha_{i}\right)}}{1-\delta_{G}+\tau\left(1-\frac{\tau_{c}}{\tau} e^{\varphi_{i t+1}}\right)\left(\frac{\alpha_{i}}{R}\right)^{\alpha_{i} /\left(1-\alpha_{i}\right)} A_{i t+1}^{1 /\left(1-\alpha_{i}\right)}}\right]}\right] \\
& =\ln \frac{(1-\beta) \kappa_{i}}{\beta \tau_{c}\left(\kappa_{i}+\gamma\right)}-\ln \left\{\left(\frac{\alpha_{i}}{R}\right)^{\alpha_{i} /\left(1-\alpha_{i}\right)} E_{t}\left[\frac{A_{i t+1}^{1 /\left(1-\alpha_{i}\right)}}{1-\delta_{G}+\tau\left(1-\frac{\tau_{c}}{\tau} e^{\varphi_{i t+1}}\right)\left(\frac{\alpha_{i}}{R}\right)^{\alpha_{i} /\left(1-\alpha_{i}\right)} A_{i t+1}^{1 /\left(1-\alpha_{i}\right)}}\right]\right\}
\end{aligned}
$$

This equation has a unique root in the interval $\left(0, \ln \tau-\ln \tau_{c}\right)$ under the following inequality conditions:

$$
\ln \frac{(1-\beta) \kappa_{i}}{\beta \tau_{c}\left(\kappa_{i}+\gamma\right)}-\ln \left\{\left(\frac{\alpha_{i}}{R}\right)^{\alpha_{i} /\left(1-\alpha_{i}\right)} E_{t}\left[\frac{A_{i t+1}^{1 /\left(1-\alpha_{i}\right)}}{1-\delta_{G}+\left(\tau-\tau_{c}\right)\left(\frac{\alpha_{i}}{R}\right)^{\alpha_{i} /\left(1-\alpha_{i}\right)} A_{i t+1}^{1 /\left(1-\alpha_{i}\right)}}\right]\right\}>0
$$

and

$$
\ln \frac{(1-\beta) \kappa_{i}}{\beta \tau_{c}\left(\kappa_{i}+\gamma\right)}-\ln \left\{\left(\frac{\alpha_{i}}{R}\right)^{\alpha_{i} /\left(1-\alpha_{i}\right)} E_{t}\left[\frac{A_{i t+1}^{1 /\left(1-\alpha_{i}\right)}}{1-\delta_{G}}\right]\right\}<0 .
$$

Note that the right-hand side of (20) is increasing with $\kappa_{i}$ and decreasing with $\tau_{c}$. The Implicit Function Theorem thus implies that $\varphi_{i t+1}$ is increasing with $\kappa_{i}$ and decreasing with $\tau_{c}$.

\section{A.5 Proof of Proposition 5}

I first solve the governor's Bellman equation in (13) by conjecturing that

$$
V\left(W_{i t}\right)=k_{w} \ln W+k_{0}
$$


and denoting $d_{i t}=\frac{D_{i t}}{G_{i t+1}}$. Then, the Bellman equation becomes

$$
\begin{aligned}
& k_{w} \ln W_{i t}+k_{0} \\
= & \max _{G_{i t+1}, d_{i t}} \gamma \ln \left(W_{i t}-\left(1-d_{i t}\right) G_{i t+1}\right)+\kappa_{i}\left(\ln G_{i t+1}-\ln G_{i t+1}^{*}\right) \\
& +\beta k_{w} E_{t}\left[\ln \left(\tau Y_{i t+1}+\left(1-\delta_{G}\right) G_{i t+1}-R d_{i t} G_{i t+1}\right)\right]+\beta k_{0} \\
= & \max _{G_{i t+1}, d_{i t}} \gamma \ln \left(W_{i t}-\left(1-d_{i t}\right) G_{i t+1}\right)+\left(\kappa_{i}+\beta k_{w}\right) \ln G_{i t+1}-\kappa_{i} \ln G_{i t+1}^{*} \\
& +E_{t}\left[\beta k_{w} \ln \left[\left(1-\delta_{G}\right)+\tau\left(\frac{\alpha_{i}}{R}\right)^{\alpha_{i} /\left(1-\alpha_{i}\right)} A_{i t+1}^{1 /\left(1-\alpha_{i}\right)}-R d_{i t}\right]\right]+\beta k_{0} .
\end{aligned}
$$

The first-order condition for $G_{i t+1}$ gives that

$$
\frac{\beta k_{w}+\kappa_{i}}{G_{i t+1}}=\frac{\gamma\left(1-d_{i t}\right)}{W_{i t}-\left(1-d_{i t}\right) G_{i t+1}} .
$$

This condition implies that

$$
G_{i t+1}=\frac{\beta k_{w}+\kappa_{i}}{\gamma+\beta k_{w}+\kappa_{i}} \frac{W_{i t}}{\left(1-d_{i t}\right)} .
$$

Then, the Bellman equation becomes

$$
\begin{aligned}
& k_{w} \ln W_{i t}+k_{0} \\
= & \max _{d_{i t}}\left(\gamma+\kappa_{i}+\beta k_{w}\right) \ln W_{i t}+\left(\kappa_{i}+\beta k_{w}\right) \ln \left(\frac{1}{1-d_{i t}}\right) \\
& +\gamma \ln \left(\frac{\gamma}{\gamma+\beta k_{w}+\kappa_{i}}\right)+\left(\kappa_{i}+\beta k_{w}\right) \ln \left(\frac{\beta k_{w}+\kappa_{i}}{\gamma+\beta k_{w}+\kappa_{i}}\right)-\kappa_{i} \ln G_{i t+1}^{*} \\
& +E_{t}\left[\beta k_{w} \ln \left[\left(1-\delta_{G}\right)+\tau\left(\frac{\alpha_{i}}{R}\right)^{\alpha_{i} /\left(1-\alpha_{i}\right)} A_{i t+1}^{1 /\left(1-\alpha_{i}\right)}-R d_{i t}\right]\right]+\beta k_{0} .
\end{aligned}
$$

Equating the coefficients of $\ln W_{i t}$ gives

$$
k_{w}=\gamma+\kappa_{i}+\beta k_{w} \Rightarrow k_{w}=\frac{\gamma+\kappa_{i}}{1-\beta} .
$$

The relevant terms for choosing $d_{i t}$ are

$$
\begin{aligned}
& \max _{d_{i t}}\left(\kappa_{i}+\beta k_{w}\right) \ln \left(\frac{1}{1-d_{i t}}\right)+E_{t}\left[\beta k_{w} \ln \left[\tau\left(\frac{\alpha_{i}}{R}\right)^{\alpha_{i} /\left(1-\alpha_{i}\right)} A_{i t+1}^{1 /\left(1-\alpha_{i}\right)}+\left(1-\delta_{G}\right)-R d_{i t}\right]\right] \\
= & \max _{d_{i t}}\left(\kappa_{i}+\frac{\beta\left(\gamma+\kappa_{i}\right)}{1-\beta}\right) \ln \left(\frac{1}{1-d_{i t}}\right) \\
& \quad+\frac{\beta\left(\gamma+\kappa_{i}\right)}{1-\beta} E_{t}\left[\ln \left[\tau\left(\frac{\alpha_{i}}{R}\right)^{\alpha_{i} /\left(1-\alpha_{i}\right)} A_{i t+1}^{1 /\left(1-\alpha_{i}\right)}+\left(1-\delta_{G}\right)-R d_{i t}\right]\right] \\
\propto & \max _{d_{i t}}\left(\frac{1-\beta}{\beta} \frac{\kappa_{i}}{\gamma+\kappa_{i}}+1\right) \ln \left(\frac{1}{1-d_{i t}}\right)+E_{t}\left[\ln \left[\tau\left(\frac{\alpha_{i}}{R}\right)^{\alpha_{i} /\left(1-\alpha_{i}\right)} A_{i t+1}^{1 /\left(1-\alpha_{i}\right)}+\left(1-\delta_{G}\right)-R d(2)^{4}\right]\right)
\end{aligned}
$$


I now analyze the debt choice of the social planner. I also conjecture that

$$
V\left(W_{i t}^{\text {planner }}\right)=k_{w} \ln \left(W_{i t}^{\text {planner }}\right)+k_{0}
$$

Then, the planner's Bellman equation in (14) becomes

$$
\begin{aligned}
& \quad V\left(W_{i t}^{\text {planner }}\right) \\
& =\max _{G_{i t+1}, C_{i t}^{t}, C_{i t}^{t-1}, E_{i t}^{G}, D_{i t}} E_{t}\left[\ln \left(C_{i t}^{t}\right)+\ln \left(C_{i t}^{t-1}\right)+\gamma \ln E_{i t}^{G}+\beta k_{w} \ln \left(W_{i t+1}^{\text {planner }}\right)+\beta k_{0}\right] \\
& =\max _{G_{i t+1}, C_{i t}^{t}, C_{i t}^{t-1}, E_{i t}^{G}, D_{i t}} E_{t}\left[\ln \left(C_{i t}^{t}\right)+\ln \left(C_{i t}^{t-1}\right)+\gamma \ln E_{i t}^{G}+\beta k_{w} \ln \left(G_{i t+1}\right)\right. \\
& \left.\quad+\beta k_{w} \ln \left(\tau\left(\frac{\alpha_{i}}{R}\right)^{\alpha_{i} /\left(1-\alpha_{i}\right)} A_{i t+1}^{1 /\left(1-\alpha_{i}\right)}+\left(1-\delta_{G}\right)-R d_{i t}\right)+\beta k_{0}\right],
\end{aligned}
$$

where $d_{i t}=\frac{D_{i t}}{G_{i t+1}}$.

The Lagrange for the maximization problem on the right-hand side is

$$
\begin{aligned}
& \ln \left(C_{i t}^{t}\right)+\ln \left(C_{i t}^{t-1}\right)+\gamma \ln E_{i t}^{G}+\beta k_{w} \ln \left(G_{i t+1}\right) \\
& +\beta k_{w} E_{t}\left[\ln \left(\tau\left(\frac{\alpha_{i}}{R}\right)^{\alpha_{i} /\left(1-\alpha_{i}\right)} A_{i t+1}^{1 /\left(1-\alpha_{i}\right)}+\left(1-\delta_{G}\right)-R d_{i t}\right)\right]+\beta k_{0} \\
& -\lambda\left(C_{i t}^{t}+C_{i t}^{t-1}+E_{i t}^{G}+G_{i t+1}-W_{i t}^{\text {planner }}-G_{i t+1} d_{i t}\right) .
\end{aligned}
$$

The first-order conditions imply

$$
\lambda=\frac{1}{C_{i t}^{t}}=\frac{1}{C_{i t}^{t-1}}=\frac{\gamma}{E_{i t}^{G}}=\frac{\beta k_{w}}{G_{i t+1}\left(1-d_{i t}\right)}
$$

and

$$
\beta k_{w} E_{t}\left[\frac{R}{\left(\tau\left(\frac{\alpha_{i}}{R}\right)^{\alpha_{i} /\left(1-\alpha_{i}\right)} A_{i t+1}^{1 /\left(1-\alpha_{i}\right)}+\left(1-\delta_{G}\right)-R d_{i t}\right)}\right]=\lambda G_{i t+1} .
$$

The budget constraint implies

$$
\frac{1}{\lambda}+\frac{1}{\lambda}+\frac{\gamma}{\lambda}+\frac{\beta k_{w}}{\lambda}=W_{i t}^{\text {planner }} \Rightarrow \lambda=\frac{2+\gamma+\beta k_{w}}{W_{i t}^{\text {planner }}} .
$$

Then,

$$
G_{i t+1}\left(1-d_{i t}\right)=\frac{\beta k_{w}}{2+\gamma+\beta k_{w}} W_{i t}^{\text {planner }}
$$

and

$$
\begin{aligned}
C_{i t}^{t} & =C_{i t}^{t-1}=\frac{1}{2+\gamma+\beta k_{w}} W_{i t}^{\text {planner }} \\
E_{i t}^{G} & =\frac{\gamma}{2+\gamma+\beta k_{w}} W_{i t}^{\text {planner }}
\end{aligned}
$$


Equating the coefficients of $\ln W_{i t}$ on both sides of the Bellman equation again gives $k_{w}=$ $\frac{\gamma+\kappa_{i}}{1-\beta}$. Thus, the relevant terms in the planner's choice of $d_{i t}$ are

$$
\begin{aligned}
& \ln \left(C_{i t}^{t}\right)+\ln \left(C_{i t}^{t-1}\right)+\gamma \ln E_{i t}^{G}+\beta k_{w} \ln \left(G_{i t+1}\right) \\
& +\beta k_{w} E_{t}\left[\ln \left(\tau\left(\frac{\alpha_{i}}{R}\right)^{\alpha_{i} /\left(1-\alpha_{i}\right)} A_{i t+1}^{1 /\left(1-\alpha_{i}\right)}+\left(1-\delta_{G}\right)-R d_{i t}\right)\right]+\beta k_{0} \\
\propto & \ln \left(\frac{1}{1-d_{i t}}\right)+E_{t}\left[\ln \left(\tau\left(\frac{\alpha_{i}}{R}\right)^{\alpha_{i} /\left(1-\alpha_{i}\right)} A_{i t+1}^{1 /\left(1-\alpha_{i}\right)}+\left(1-\delta_{G}\right)-R d_{i t}\right)\right] .
\end{aligned}
$$

It is interesting to note that the two terms in (24) for the governor's debt choice are the same as the two terms in (25) for the planner's debt choice, except that the coefficient of the first term for the governor's debt choice is larger than that for the planner's choice. I thus write the objectives of the governor and the planner in the following general form

$$
\max _{d_{i t}} \Psi \ln \left(\frac{1}{1-d_{i t}}\right)+E_{t}\left[\ln \left(\tau\left(\frac{\alpha_{i}}{R}\right)^{\alpha_{i} /\left(1-\alpha_{i}\right)} A_{i t+1}^{1 /\left(1-\alpha_{i}\right)}+\left(1-\delta_{G}\right)-R d_{i t}\right)\right],
$$

where the coefficient of the first term $\Psi$ is 1 for the planner's choice and $\frac{1-\beta}{\beta} \frac{\kappa_{i}}{\gamma+\kappa_{i}}+1$ for the governor's choice.

The first-order condition of the debt choice is

$$
\underbrace{\Psi \frac{1}{1-d_{i t}}}_{f_{1}\left(d_{i t}\right)}-\underbrace{E_{t}\left[\frac{R}{\tau\left(\frac{\alpha_{i}}{R}\right)^{\alpha_{i} /\left(1-\alpha_{i}\right)} A_{i t+1}^{1 /\left(1-\alpha_{i}\right)}+\left(1-\delta_{G}\right)-R d_{i t}}\right]}_{f_{2}\left(d_{i t}\right)}=0 .
$$

Due to the logarithmic utility for all agents in the model, neither the governor nor the planner would engage in any possibility of default. Thus, they would both choose debt $d_{i t} \in\left[0, \frac{1-\delta_{G}}{R}\right]$ so that their budgets would never turn negative. Note that both $f_{1}(d)$ and $f_{2}(d)$ are positive and increasing. The following conditions ensure an interior solution to this first-order condition:

$$
f_{1}(0)>f_{2}(0) \text { and } f_{1}\left(\frac{1-\delta_{G}}{R}\right)<f_{2}\left(\frac{1-\delta_{G}}{R}\right),
$$

which are equivalent to

$$
\Psi>E_{t}\left[\frac{R}{\tau\left(\frac{\alpha_{i}}{R}\right)^{\alpha_{i} /\left(1-\alpha_{i}\right)} A_{i t+1}^{1 /\left(1-\alpha_{i}\right)}+\left(1-\delta_{G}\right)}\right] \text { and } \Psi<E_{t}\left[\frac{R+\delta_{G}-1}{\tau\left(\frac{\alpha_{i}}{R}\right)^{\alpha_{i} /\left(1-\alpha_{i}\right)} A_{i t+1}^{1 /\left(1-\alpha_{i}\right)}}\right] \text {. }
$$

As the coefficient $\Psi$ is larger for the governor's decision, the governor's debt choice is higher in order to satisfy the first-order condition. Furthermore, the governor's choice is increasing with $\Psi$ and thus with the governor's career incentive coefficient $\kappa_{i}$. 


\section{A.6 Proof of Proposition 6}

To solve the Bellman equation specified in (16), I again assume $V\left(W_{i t}\right)=k_{w} \ln \left(W_{i t}\right)+k_{0}$, as suggested by the derivation in the previous section. Then, by substituting in $E_{i t}^{G}=$ $W_{i t}+D_{i t}-G_{i t+1}$ and rescaling the choice variables as

$$
g_{i t+1}=\frac{G_{i t+1}}{W_{i t}} \text { and } d_{i t}=\frac{D_{i t}}{G_{i t+1}}
$$

I have

$$
\begin{array}{cc}
\max _{g_{i t+1}, d_{i t}} & \gamma \ln W_{i t}+\gamma \ln \left[1-\left(1-d_{i t}\right) g_{i t+1}\right]+\kappa_{i}\left(\lambda+\lambda^{\prime}\right)(1-\alpha)\left(\ln g_{i t+1}-\ln g_{i^{\prime} t+1}\right) \\
& -\phi_{i}\left(\lambda+\lambda^{\prime}\right)^{2}(1-\alpha)^{2}\left(\ln g_{i t+1}-\ln g_{i^{\prime} t+1}\right)^{2} \\
& +\beta k_{w}\left[\ln W_{i t}+\ln g_{i t+1}+E_{t}\left[\ln \left(\tau\left(\frac{\alpha_{i}}{R}\right)^{\frac{\alpha_{i}}{1-\alpha_{i}}} A_{i t+1}^{\frac{1}{1-\alpha_{i}}}+\left(1-\delta_{G}\right)-R d_{i t}\right)\right]\right]+\beta k_{0} .
\end{array}
$$

The first-order condition for $g_{i t+1}$ gives

$$
\frac{\gamma\left(1-d_{i t}\right)}{1-\left(1-d_{i t}\right) g_{i t+1}}=\left[\beta k_{w}+\kappa_{i}\left(\lambda+\lambda^{\prime}\right)(1-\alpha)-\phi_{i}\left(\lambda+\lambda^{\prime}\right)^{2}(1-\alpha)^{2}\left(\ln g_{i t+1}-\ln g_{i^{\prime} t+1}\right)\right] \frac{1}{g_{i t+1}},
$$

which in turn gives

$$
\frac{1}{\left(1-d_{i t}\right) g_{i t+1}}=1+\frac{\gamma}{\beta k_{w}+\kappa_{i}\left(\lambda+\lambda^{\prime}\right)(1-\alpha)-\phi_{i}\left(\lambda+\lambda^{\prime}\right)^{2}(1-\alpha)^{2}\left(\ln g_{i t+1}-\ln g_{i^{\prime} t+1}\right)},
$$

which has a unique root for $g_{i t+1}$ in $(0, \infty)$, for a given $d_{i t}$. This root is increasing with both $g_{i^{\prime} t+1}$ and $d_{i t}$.

Equating the coefficients of $\ln W_{i t}$ on both sides gives

$$
k_{w}=\gamma+\beta k_{w} \Rightarrow k_{w}=\frac{\gamma}{1-\beta} .
$$

Then, the leverage choice is determined by

$$
\begin{aligned}
& \max _{d_{i t}} \gamma \ln \left[1-\left(1-d_{i t}\right) g_{i t+1}\right]+\kappa_{i}\left(\lambda+\lambda^{\prime}\right)(1-\alpha)\left(\ln g_{i t+1}-\ln g_{i^{\prime} t+1}\right) \\
& -\phi_{i}\left(\lambda+\lambda^{\prime}\right)^{2}(1-\alpha)^{2}\left(\ln g_{i t+1}-\ln g_{i^{\prime} t+1}\right)^{2} \\
& +\beta k_{w}\left[\ln g_{i t+1}+E_{t}\left[\ln \left(\tau\left(\frac{\alpha_{i}}{R}\right)^{\frac{\alpha_{i}}{1-\alpha_{i}}} A_{i t+1}^{\frac{1}{1-\alpha_{i}}}+\left(1-\delta_{G}\right)-R d_{i t}\right)\right]\right],
\end{aligned}
$$

where $g_{i t+1}\left(d_{i t} ; g_{i^{\prime} t+1}\right)$ is given by $(26)$. This optimization problem leads to an optimal choice

$$
d_{i t}=d_{i t}\left(g_{i^{\prime} t+1}\right) .
$$


Symmetrically, I have

$$
d_{i^{\prime} t}=d_{i^{\prime} t}\left(g_{i t+1}\right) .
$$

These two equations jointly determine the two governors' debt choices and lead to rat-race dynamics.

\section{References}

Bai, Chong-En, Chang-Tai Hsieh, and Zheng Song (2016), The long shadow of China's fiscal expansion, Brookings Papers on Economic Activity, Fall, 129-165.

Bai, Chong-En, Xilu Chen, Wei Chen, Chang-Tai Hsieh, and Zheng Song (2018), A forensic examination of China's national accounts, Working paper, CUHK.

Bai, Chong-En and Yingyi Qian (2010), Infrastructure development in China: The cases of electricity, highways, and railways, Journal of Comparative Economics 38, 34-51.

Barro, Robert (1990), Government spending in a simple model of endogeneous growth, Journal of Political Economy 98(5, Part 2), S103-S125.

Brandt, Loren and Xiaodong Zhu (2000), Redistribution in a decentralized economy: Growth and inflation in China under reform, Journal of Political Economy 108, 422-439.

Chen, Zhuo, Zhiguo He, and Chun Liu (2017), The financing of local government in China: Stimulus loan wanes and shadow banking waxes, Working paper, University of Chicago.

Cheremukhin, Anton, Mikhail Golosov, Sergei Guriev, and Aleh Tsyvinski (2017), The economy of People's Republic of China from 1953, Working paper.

Diamond, Peter (1965), National debt in a neoclassical growth model, American Economic Review 55(5), 1126-1150.

Easterly, William, and Sergio Rebelo (1993), Fiscal policy and economic growth, Journal of Monetary Economics 32(3), 417-458.

Fan, Ziying, Wei Xiong, and Li-An Zhou (2016), Information distortion in hierarchical organizations: A study of China's Great Famine, Working paper, Princeton University.

Gibbons, Robert, and Kevin J. Murphy (1992), Optimal incentive contracts in the presence of career concerns: Theory and evidence, Journal of Political Economy 100(3): 468505. 
Glomm, Gerhard, and Balasubrahmanian Ravikumar (1994), Public investment in infrastructure in a simple growth model, Journal of Economic Dynamics and Control $18(6), 1173-1187$.

Holmstrom, Bengt (1982), Managerial incentive problems: A dynamic perspective, in Essays in Economics and Management in Honor of Lars Wahlbeck, Helsinki: Swedish School of Economics.

Hortacsu, Ali, Shushu Liang, and Li-An Zhou (2017), Chinese local officials and GDP data manipulation: Evidence from night lights data, Working paper, University of Chicago and Peking University.

Hsieh, Chang-Tai, and Peter Klenow (2009), Misallocation and manufacturing TFP in China and India, Quaterly Journal of Economics 124, 1403-1448.

Hsieh, Chang-Tai, and Zheng Michael Song (2015), Grasp the large, let go of the small: The transformation of the state sector in China, Brookings Papers on Economic Activity, Spring, 295-366.

Lau, Lawrence J., Yingyi Qian, and Gerard Roland (2000), Reform without losers: An interpretation of China's dual-track approach to transition, Journal of Political Economy 108, 120-143.

Li, Hongbin and Li-An Zhou (2005), Political turnover and economic performance: The incentive role of personnel control in China, Journal of Public Economics 89(9-10), 1743-1762.

Li, Xi, Xuewen Liu and Yong Wang (2015), A model of China's state capitalism, Working paper, HKUST.

Maskin, Eric, Yingyi Qian, and Chenggang Xu (2000), Incentives, information, and organizational form, Review of Economic Studies 67(2), 359-378.

Qian, Yingyi (2017), How Reform Worked in China, MIT Press.

Song, Zheng, Kjetil Storesletten, and Fabrizio Zilibotti (2011), Growing like China, American Economic Review 101(1), 196-233.

Song, Zheng and Wei Xiong (2018), Risks in China's financial system, Annual Review of Financial Economics, forthcoming.

Stein, Jeremy (1989), Efficient capital markets, inefficient firms: A model of myopic corporate behavior, Quarterly Journal of Economics, 104(4), 655-669.

$\mathrm{Xu}$, Chenggang (2011), The fundamental institutions of China's reforms and development, Journal of Economic Literature 49(4), 1076-1151. 
Young, Alwyn (2003), Gold into base metals: Productivity growth in the People's Republic of China during the reform period, Journal of Political Economy 111, 1220-1261.

Yu, Jihai, Li-An Zhoub and Guozhong Zhu (2016), Strategic interaction in political competition: Evidence from spatial effects across Chinese cities, Regional Science and Urban Economics 57, 23-37.

Zhang, Yuanyan Sophia and Steven Barnett (2014), Fiscal vulnerabilities and risks from local government finance in China, Working paper, IMF.

Zhu, Xiaodong (2012), Understanding China's economic growth: Past, present and future, Journal of Economic Perspectives 26, 103-124. 